Portland State University

PDXScholar

1978

\title{
A Study of Partner Attitudes Related to Male Involvement in Contraception at Planned Parenthood, Portland, Oregon
}

\author{
Patricia Long Burnet \\ Portland State University \\ Rhonda Lee Jack \\ Portland State University \\ Kathleen Margaret Leeson \\ Portland State University
}

Follow this and additional works at: https://pdxscholar.library.pdx.edu/open_access_etds

Part of the Family, Life Course, and Society Commons, and the Social Work Commons Let us know how access to this document benefits you.

\section{Recommended Citation}

Burnet, Patricia Long; Jack, Rhonda Lee; and Leeson, Kathleen Margaret, "A Study of Partner Attitudes Related to Male Involvement in Contraception at Planned Parenthood, Portland, Oregon" (1978). Dissertations and Theses. Paper 2691.

https://doi.org/10.15760/etd.2687

This Thesis is brought to you for free and open access. It has been accepted for inclusion in Dissertations and Theses by an authorized administrator of PDXScholar. Please contact us if we can make this document more accessible: pdxscholar@pdx.edu. 
A Study of Partner Attitudes Related to Male Involvement in Contraception at Planned Parenthood Portland, Oregon

\author{
By \\ Patricia Long Burnet \\ Rhonda Lee Jack \\ Kathleen Margaret Leeson
}

A Practicum Submitted in Partial Fulfillment of Requirements for the degree of

MASTERS OF SOCIAL WORK

Portland State University

1978 
To The Office of Graduate Studies:

The members of the Committee Approve the Practicum of Patricia Long Burnet, Rhonda Lee Jack and Kathleen Margaret Leeson submitted June 5, 1978.

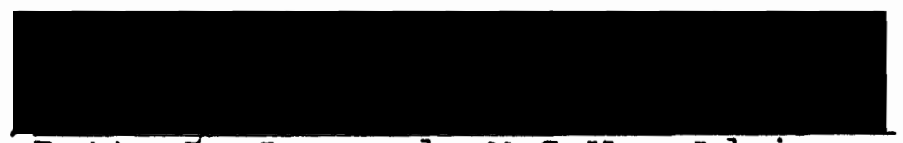

Betty 7 . Leonard, M.S.W., Advisor

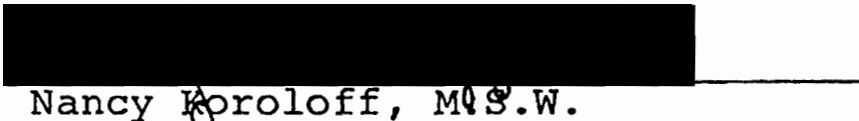

Nancy foloff, MUS.W.

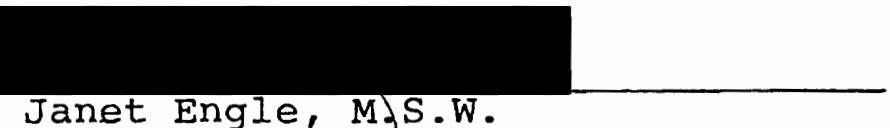


TABLE OF CONTENTS

PAGE

LIST OF TABLES •. • . . . . . . . . . . . V V

LIST OF FIGURES . . . . . . . . . . . . . . vi

CHAPTER

I INTRODUCTION . . . . . . . . . . . . . I

Problem, Focus and Goals

II REVIEW OF THE LITERATURE . . . . . . . . 3

The Status of Contraceptive Roles

Attitudes Towards Responsibility

Partner Influence on Contraception

The Emergence of Male Programs and summary

III DESCRIPTION OF THE STUDY . . . . . . 29

Objectives

Instrument

Pilot Study

Population and Sample

Data Collection

Statistical Analysis

Limitations of the Study

IV ANALYSIS OF THE DATA . . . . . . . 34

Demographic Variables

Men's Relationship to the Clinic

Involvement with Birth Control

Choice of Methods

Sexual History

Interest in Classes

Additional Comments 
$\mathrm{V}$ CONCLUSION AND RECOMMENDATIONS • . . . . 70

REFERENCE LIST. - . . . . . . . . . . . . 78

REFERENCE NOTES . . . . . . . . . . . . . 83

BIBLIOGRAPHY : ADDITIONAL SUGGESTED READINGS • • • . 84

APPENDIX • • . . . . . . . . . . . . . 86

A. Chi Square Tables

B. Cross-Tabulation Tables

C. Men's Comments

D. Women's Comments

E. Involving Men in Family Planning

F. Male Questionnaire

G. Female Questionnaire 
IIST OF TABLES

TABLE

PAGE

I Present Marital Status . . . . . . . 36

II Presently Living With Sexual Partners . . . 36

II Educational Aspirations . . . . . . . . 38

IV Initiator of Visit to Portland Planned

Planned Parenthood, by Sex . . . . . . 40

V Prior Obtainment of Birth Control . . . . . 41

VI Felt Involvement in Decision-Making . . . . 45

VII Responsibility for Birth Control • . . . . . 47

VIII Birth Control Method Unacceptable to

Respondent, Ranked . . . . . . . 49

IX Birth Control Method Perceived to Be

Unacceptable to Partner, Ranked . . . . 50

X Respondents' Reasons for Condom Non-Use • . 52

XI Sexual Knowledge at First Intercourse . . . 54

XII Present Sexual Knowledge . . . . . . . 55

XIII Perception of Peer!s Practicing Sexual

Intercourse Without Birth Control . . . 59

XIV Class Attendance . . . . . . . . . . 66

XV Women's Preference for Partner to Attend or Not to Attend Classes . . . . . . . 
TABLE

PAGE

XVI Birth Control Decision-Making Correlated

With Felt Responsibility,Males only . •

XVII Consent to Sexual Intercourse Without

Birth Control . . . . . . . . . 86

XVIII Initiator of Visit to Portland Planned

Parenthood, by Sex . . . . . . . 87

XIX Felt Involvement in Decision-Making . . . . 87

$\mathrm{XX}$ Responsibility for Birth Control . . . . . 88

XXI Rating of Present Knowledge . . . . . . . 88

XXII Initiator of Sexual Intercourse, By Sex . • 89 


\section{LIST OF FIGURES}

FIGURES

PAGE

1. Age of Respondents . . . . . . . . 35

2. Completed Education . . . . . . . . 38

3. Age at First Sexual Intercourse, In Years . 60

4. Age of First Use of Birth Control, In Years 61 


\section{CHAPTER I.}

\section{INTRODUCTION}

\section{PROBLEM, FOCUS, AND GOALS}

In spite of the relative ease of accessibility to reliable contraception, unplanned pregnancy continues to be a major social problem for both society and for those individuals personally involved. The growing furor over adolescent unplanned pregnancy has not only led to arguments over abortions on legal, financial, and moral levels but has resulted in studies pertaining to non-use of birth control among all ages. Contraceptives are not being used as widely and effectively as they could be.

One purported casual factor of this problem is the fact that family planning has virtually excluded half of the possible target population by ignoring males in birth control education and dissemination. This study focuses on partner attitudes and behavior, and male involvement in the family planning process.

The primary goal of this research is to explore the male's role (or lack of it) in family planning. A further goal is to increase awareness among practitioners in the field and among the general public, regarding the importance 
of male involvement. Stereotypes and norms prevail too often, clouding actual practice and desires. For many years males have tended to respond to questions regarding birth control decision-making with: "1) it's the woman who gets pregnant, not me; 2) it's her problem, let her deal with it; 3) what! me worry?; or 4) but there's more things she can use, so why bother" ("Six Hints for Developing Your Male Education Program," Chicago Planned Parenthood, Note 4). There are indications that such attitudes toward involvement of the male may slowly be changing and evolving toward a more egalitarian participation.

A search for causal factors must look beyond "unmotivated men," and consider socialization and a practiced exclusion of their thoughts and feelings. Increasing numbers of clinics have been initiating male oriented outreach programs to provide information and services relating to birth control and sexuality.

This study provides a basis and rationale for the accelerated inclusion of men in contraceptive practices. 
CHAPTER II

LITERATURE REVIEW

\section{THE STATUS OF CONTRACEPTIVE ROLES}

Historically, control of conception has been primarily a male responsibility (Deys \& Potts, 1972; Free \& Alexander, 1976; Lewy, 1977; Luker, 1975), accomplished by the use of withdrawal and condoms. Deys and Potts (1972) note that the oldest and most widely used method of contraception in the world is coitus interruptus. The practice is described in the Bible and the Koran. The Talmud describes it as "threshing inside and winnowing outside" (p. 288).

Male methods not withstanding, organized family planning efforts in America have been essentially women's issues, propelled by the fact that females have had the major involvement in childbearing and childrearing (Guttmacher, Best, \& Jaffe, 1969) and the attitude that it was ". . the right of American women to control their own fertility" (Veerhusen, 1974, p. 186).

The diaphragm, invented in 1882, represented one of the first female methods of conception control (Women's Health Care Collective, 1976, p. 182), and it was "The Method" promoted by Planned Parenthood from the time of 
its establishment in the 1920's until recently, primarily because it was a medical method which women could control and was perceived to be more effective than other alternatives (Veerhusen, 1974, pp. 186-187).

While "for many years the diaphragm was the method most frequently prescribed by doctors and birth control centers" (Guttmacher et al., 1969, p. 57), and while other non-medical methods tended to be dismissed out-of-hand by organized services (Veerhusen, 1974), various surveys of segments of the American population such as those taken in 1933-1934 (Himes, 1963), 1955 (Freedman, Whelpton \& Campbell, 1959), and 1960 (Westoff and Ryder, 1973) show evidence that other methods, including male methods such as the condom, remained popular and were widely utilized.

Veerhusen (1974, p. 187) notes that the arrival of the pill in 1960 further institutionalized the "traditional approach" that birth control should be "clinical" and a female province.

The pill surpassed condoms in frequency as the most recently used method of contraception reported by women for the first time in 1965 (U.S. Bureau of the Census, 1971, p. 53), and it is currently the most popular method of birth control among married white women surveyed in the United States according to Westoff and Jones (1977), and women served by "organized family planning services," according 
to The Alan Guttmacher Institute (1976). Zelnik and Kanter (1976) note that pill use has increased substantially anong teenage women over the past five years, and several studies (Fujita, Wagner \& Pion, 1973; Settlage, Baroff \& Cooper, 1973; Sorensen, 1973) have shown that it is a method of relative popularity among adolescents. Lane (1973) reports on methods chosen by young women at a teen clinic. The pill, followed by the I.U.D., was the most often chosen method.

Luker (1975), in her volume about abortion and risktaking, discusses the fact that methods other than the pill or I.U.D. necessitate male involvement in birth control to a greater or lesser degree, "... since all are used within the context of sexual intercourse, there is an invariant threshold at which the male must acknowledge their presence and involve himself more or less directly in the decision to contracept" (pp. 124-125). However, widespread pill use and the use of other female methods of contraception has caused the use of these "couple methods" to dwindle, and placed the onus of responsibility on women, according to Luker. She notes that female methods have been developed on the premise that women are better contraceptors because of their ability to become pregnant. She contends that this is a social, rather than biological definition because "... both men and women become pregnant -- 
immaculate conceptions are virtually unknown in the literature" (p. 125). The focus on female methods has also made women totally accountable for pregnancy, further distancing men from responsibility. She notes that:

The development of the pill and the I.U.D. rested on the assumption that men were too irresponsible and too unmotivated to use contraceptives, and the development of the pill and the I.U.D. and its subsequent social impact make that assumption true, whether or not it had been so before (p. 127).

Iuker points out that male non-involvement in birth control is a factor which influences female contraceptive "risk-taking." In the concluding chapter of her book, she discusses possible ways of ameliorating the current sociallyinduced situation regarding contraceptive responsibility, among them, the inclusion of males in clinics, either as partners or in programs designed for men, and a change in clinic policy which would take contraceptives out of the realm of an exclusively female province (p. 150-151).

Barber (1975) discusses unmarried fätherhood in Britain and notes that the focus on female methods over time, and the fact that male methods are unpleasant and less reliable by comparison, has left men out of the birth control process:

The reliable methods are those which do not curtail physical sensations and which are designed exclusively for female use. underlying these developments is an honest recognition that women have most to lose by becoming pregnant, but the effect is to further disāssociate men from what is an undeniable partner- 
ship. Then again, intrauterine devices and oral contraceptives can be effectively limited as to availability by the necessity to fit and to prescribe accurately. In view of this it is very difficult to argue against men, and particularly unmarried fathers, who say that it is the woman's responsibility, not theirs, to contracept (p. 162).

He further notes that agencies which deal with birth control should stress mutual responsibility, albeit a difficult task when male methods are lagging behind. He states, "Because of our neglect of male contraceptive methods I believe we encourage irresponsibility in men, with the result that many become unmarried fathers" (p. 163). However, not all males have divorced themselves from contraceptive responsibility, despite the influence of recent social conditioning. Deys and Potts (1972) have discussed the use of male methods in many countries and conclude that male decision-making about use of contraception and the choice of method is widespread. They define a "male method" as "a method of birth control where the male partner has assumed the primary role in the decision to control the couple's fertility" (p. 291). They cite examples of Moslem males who buy birth control pills for use by their wives and males in lower levels of British society who decide whether their wives use the pill. In these contexts, the pill is no longer defined as a female method. In their opinion, "... the decision to acquire and use a contraceptive method takes priority over which 
partner wears, eats, inserts, or otherwise uses the method" (p. 291).

The authors also refer to situations in various cultures where women are the ones who decide to utilize traditional male methods, citing women who buy condoms or take the responsibility of seeing that they are used during intercourse, or women who may even "control withdrawal methods through the use of suitable gymnastics" (p. 291). Given these definitions, contraception need not be interpreted as being gender-specific, but related to involvement and decision-making.

More specific indicators of male involvement may be found in studies regarding male method use.

one indicator of male involvement in contraception is the number of men who now obtain vasectomies. Lewy (1977, p. 107) notes that over a million vasectomies were performed in the United States in 1973, as compared to about 750,000 in 1970. Westoff and Jones (1977, p. 155) estimate that the number of vasectomies is almost as great as the number of female sterilizations in America among white, married couples.

It should be noted that vasectomy is a method limited to men of an age to have completed their desired family size. It is, therefore, a method which is not commonly considered by very young couples or single people, with the possible 
exception of those who have decided they want no children. one segment of the American population where male methods such as condoms and withdrawal are frequently used is in the unmarried teenage population. Several studies (Arnold, 1972; Akpom, Akpom, \& Davis, 1976; Finkel and Finkel, 1975; Fujita et al., 1973; Kantner and Zelnik, 1973; Kirkendal1, 1961; Settlage et al., 1973; Sorensen, 1973) have produced data showing that relatively high percentages of their teenage populations have relied on the use of male contraception. The reliance on non-medical methods is more frequent among younger teens (Zelnik \& Kantner, 1976), but the methods are also used by teenagers of all ages prior to seeking clinic services (Settlage et al., 1973).

Harvey (1974) points out that "throughout the world there is a consistent demand for condoms, both for contraception and venereal disease prevention, whether or not there is a high level of use of medical methods of birth control" (p. 36). In 1975, condoms ranked fourth as a method reported used by married white women. They were surpassed by the pill and sterilization for both sexes, but still accounted for about one-tenth of all method use, even though their popularity has greatly declined from pre-pill days (Westoff \& Jones, 1977).

Condoms, it appears, are being used, despite objections to the method which are long-standing. over $60 \%$ 
of the boys in Gilbert \& Mathews (1974) study agreed that "using a condom cuts down on the feeling a guy gets during intercourse" (p. 170). Darrow's respondents (1974, p. 175) were asked to choose among 15 possible reasons for not using condoms. Most said they were an "interference," or were "unnatural," "unsatisfying" or "messy and uncomfortable." Fewer respondents listed reduction of pleasure as a reason for non-use; no one said they were too expensive.

Recently, however, some proponents of the condoms have attempted to give it more credence as a desirable method of birth control by citing its high rate of effectiveness, ready availability, lack of side effects, and reasonable cost (Free \& Alexander, 1976; Arnold, 1973). In Scales'(1977) view, "the condom offers many advantages to the young and unmarried (i.e., the sexually unsanctioned): It is inexpensive, relatively easy to obtain, and easy to carry around and have available for sex which is typically unpredictable" (p. 212).

Scales (1977) reviewed literature on male involvement and noted:

It is evident that a large percentage of teenage contraceptive behavior depends on males' perception of their responsibility for using contraception, and on their willingness and ability to assume that responsibility (p. 2ll).

Concommittant with that statement, however, is his observation that: 
Institutional and social-cultural standards about sexual communication and the male's role in sexual decisions...have tended to discourage men from some crucial participation in family planning (p. 211-212).

In his conclusions, scales discusses the fact that a great deal of effort has been spent on researching female methods while little emphasis has been directed to encouraging male involvement, despite the obvious fact that male methods are used by many teens.

What seems most unsettling about this current lack of emphasis is that the pill is apparently becoming the method of choice among young women. As use of this kind of non-disruptive method increases, it is possible that males, no longer using contraception in significant numbers, may concurrently decrease their emotional involvement in birth prevention. The low levels of reported communication about contraception between young partners lends credence to this view. The net effect of these patterns could be an estrangement between the sexes and a social force that perpetuates and/or re-establishes conventional sex role behavior. Few would deny that sexism is perpetuated if women as a class are excluded from occupational opportunities; but the exclusion of males from contraceptive opportunities is itself a form of sexism that current trends may be encouraging ( $p .220$ ).

Scales also notes that young people need education and open communication in order not to view male or couple contraceptives as simply being "disruptive," but as a part of partner interaction. In his view:

... this kind of perspective can only develop if efforts are made to increase males' concern with the possibility of pregnancy and to encourage their willingness to share responsibility for preventing pregnancy as a necessary part of nonexploitative relationships (p. 220). 


\section{ATTITUDES TOWARD RESPONSIBILITY}

Several studies have discussed the issue of whether or not males are willing to take responsibility for and/or share in the responsibility of birth control. Female attitudes about the issue were also addressed in some cases. Schofield (1973) studied young adults in Britain. Among the many aspects of sexuality he addressed was contraceptive use. He asked his respondents who should be responsible for birth control. Of those who replied,

Thirty-nine percent ( 40 percent men, 37 percent women) thought it should be a joint decision; 21 percent ( 25 percent men and 14 percent women) thought it was the men's responsibility; 6 percent ( 10 percent men and 24 percent women) thought it was the woman's responsibility. The majority think it should be a joint decision and this implies that the subject must be discussed (p. 125).

Cartwright (1970, p. 149) found that over threequarters of the couples she studied felt both partners ought to decide to use contraception. Of the remainder of the men who did not classify the decision as mutual, more men than women said it should be the male prerogative. The women who did not feel it was a mutual responsibility were distributed evenly between those who thought it was a female domain and those who saw it as a male responsibility.

Finkel and Finkel (1975) studied 421 male teenagers of varying ethnic backgrounds. Portions of their research were aimed at male attitudes toward birth control. One of their 
questions reflected attitudes specifically about responsibility, and another probed for feelings about use. Over half (54.5\%) of their respondents felt birth control should be used solely by the female, yet nearly $60 \%$ thought "a male who uses a rubber shows respect for his girlfriend" (p. 258). Hale, Vadies, and Fryer (Note 1) studied 1,017 teenaged males' attitudes about birth control and found that slightly less than half (45.6\%) of their respondents gave affirmative replies to statements placing the onus of responsibility on the female. Nearly three-quarters of them did not think that "A guy should use birth control whenever possible." The authors noted that males may be evincing a more egalitarian viewpoint about sharing responsibility than was found in the Finkel's study, but responses about male use of birth control also indicate that "they are not prepared to shift too suddenly toward the direction of 'more' or 'total' responsibility on the male population" (p.4).

Spillane and Ryser (1975, p. 71) conducted a comprehensive study on male fertility. Among their findings was the observation that the majority (56\%) of the married men they studied would be willing to use a male birth control pill. They further observe that "the men in this study give overwhelming approval to family planning and agree that family planning services should be made available 
to men" (p. 102).

Peer use of contraception was another factor explored by Spillane and Ryser, who note: "Men who thought that most of their friends use birth control are the most likely to use birth control methods themselves and to choose medical methods" (p. 67).

Balswick (1972, p. 196) noted a less enthusiastic response on the part of the married lowex class men he studied. Forty-seven percent of them would not want to take male pills, while $12 \%$ were undecided and $41 \%$ would not object to the use of a male pill. Additionally, slightly over half of the men did not want their wives to use pills, and $59 \%$ of them would not want a vasectomy. While various reasons are listed by the respondents for their objections to these methods, Balswick perceives a resistance to use of these methods by lower class men and notes:

It would seem that there is a need to reeducate the lower-class male to the idea that voluntary sterilization, be it temporary by means of a pill or permanent by means of vasectomy, should not be thought of as emasculation (p. 199).

Arnold and Cogswell (1971) conducted a feasibility study on a condom distribution project and found condom use among inner-city adolescents increased substantially after the project was initiated. They concluded:

Inner-city adolescent men, also contrary to many present-day stereotypes, wish to prevent unwanted births; over two-third of our recipients indicated that reason for their condom use. We infer from this datum that young men are willing to assume a sizeable share of responsibility for family planning ( $p .750)$. 
Gilbert and Mathews (1974, pp. 169-170) questioned adolescent males, most of whom were attending a teen clinic with their girlfriends, on their attitudes about condoms and found that the majority would probably use them "for birth control, for prevention of V.D., and at the partner's request" ( $p .169)$. Responses to a vignette about a boy who does not use a condom with his girlfriend when he knows she is unprotected indicated that many of the respondents (48\%) felt he should have discussed the matter with the girl before proceeding. The remainder felt he should have used the condom or advised the girl to get protection, with the exception of $6 \%$ who were in agreement with the non-use of the condom. The authors conclude that "most of the boys are accepting of male involvement in contraceptive responsibility, though there are variances in their perceptions of how the male is expected to fulfill this role" (p. 170).

Sorensen (1973) conducted a national sample of American adolescent sexual behavior and attitudes and found that "89\% of all boys currently having intercourse are often or sometimes worried about their sex partners becoming pregnant, compared with $71 \%$ of the girls currently having intercourse" (p. 325).

While these studies have shown some favorable responses to involvement by males, a lack of responsibility 
or interest in participation on the part of some men is illustrated in the following sources.

Sorensen reports the following observations about the boys in his sample who were interviewed:

In our interviews no unmarried boy expressed the desire for his sex partner to become pregnant. Boys in the national sample were not asked whether they care if their sex partner becomes pregnant. However, many boy respondents in our interviews expressed few or no feelings of responsibility concerning their sex partner's pregnancy. Abortion, the gradual disappearance in most communities of shotgun marriages, and the use of the pill and intrauterine devices which a boy need never see or hear about all tend to lessen boys' feelings of responsibility toward the possible pregnancy of their sex partners (p. 304-305).

Luker (1975), in discussing the lack of male involvement in birth control, cites an unpublished study conducted in a local clinic which showed that "fewer than one out of ten high school and college-age men asks a woman at first intercourse. whether she is contraceptively protected" (p. 134). Luker opines that two factors which may produce such a situation are prevalence of pill use among women and the availability of abortion.

Women themselves may often feel they should carry sole responsibility. Evidence of female's expectations that they should be the ones to use contraception is given by the girls in Sorensen's (1973) study, who do not appear to be supportive of male responsibility. Of all the teenage women sampled, very few (14\%) said contraception should be 
up to the man, and many thought males untrustworthy (p. 322).

However, Arnold (1973) in discussing the condom

distribution program among inner-city males noted:

In our experience we found that males were expected

by teen-age females to take the initiative in preventing pregnancies. In our community they were believed by women to be more generally knowledgeable about sex matters, including contraception (p. 140).

Attitudes about responsibility and willingness to assume or share it also may be related directly to partner interaction, and the degree of communication and cooperation that exists between them.

In his study, Schofield (1973) followed his query about who should take contraceptive responsibility by asking "all the married informants who did not take responsibility for birth control themselves if they insisted that their spouse took precautions. Less than half (42\%) said they did" (p. 125). He postulates that this attitude of irresponsibility or unwillingness to discuss the problem is also present in the unmarried ranks.

Furstenburg, Gordis and Markowitz (1969) note that the use of male contraception often posed problems for young women because the boys sometimes showed reluctance to use a method:

Many respondents attributed irregular use of birth control to their boyfriend's lack of cooperation. On the other hand, some girls admitted they had not pressed their boyfriends to use birth control. As 
one girl put it: 'I asked him one time why he didn't use anything and he said because I didn't ever tell him to' (p. 39).

Scales (1977, p. 218) reviewed literature on communication about contraception and concluded that it is often a factor which is lacking between partners.

Barber (1975) observes that the partner of either sex may expect the other to take responsibility and notes that "both sexes, especially when young, suffer from embarrassment which still surrounds the topic and therefore seldom discuss it responsibly" (p. 163). The problem is compounded by the fact that many boys simply assume women are protected because of the publicity about use of female methods.

Lindeman (1974) notes that differing expectations about whose responsibility it is to contracept often cause confusion, especially in the light of the waning double standard and the sexual activity of females. She states:

New twists on the double standard come out when questions like these are asked: Who is supposed to start the talk about birth control? Who decides whether to use it? Who initiates the action to get birth control? Who should provide it? (p. 27).

Furthermore, there are no guidelines for communication about the matter. In the case of single people, "etiquette" may prevent discussion, leaving each partner to assume the other is supposed to use contraception. Lindeman observes that "communication on the physical level does not guarantee 
communication on the level that is necessary for checking about birth control" (p. 28).

one reason why communication about whether or not birth control measures have been, taken is important is the fact that most female methods are inconspicuous.

Sorensen (1973, p. 317) notes that some discrepancies in the type of method use reported by the boys and girls in his study may be partially due to the fact that the boys may not have knowledge of birth control use by the girl because they may not ask the girl, and female methods often cannot be seen.

In a later chapter Sorensen (1973) discusses five reasons for neglecting to use birth control. One is particularly relevant to the discussion of communication:

Elements of casualness, spontaneity, and misinformation seem to characterize the sexual experiences of many adolescents. Protection from pregnancy has a relatively low priority for many adolescents. But awareness is often stifled by the sex partners themselves. The boy often avoids raising the question because he does not want to assume responsibility or cause the girl to change her mind. In many cases the girl does not want to acknowledge the possible consequences of sexual intercourse ( $p .371$ ).

Several studies (Akpom et al., 1973; Reichelt \& Werley, 1975; Settlage et al., 1973) have found that many teens have been sexually active for some time before coming to a clinic, some for over a year. Some have used contraception prior to coming, and the great majority of 
these relied on non-medical methods. Many of them have used no method at all or have used a method sporadically. This gap, or time lag between first intercourse and use of birth control has been discussed by several sources (Iindeman, 1974; Schofield, 1973; Zelnik \& Kantner, 1976).

The data in Zelnik and Kantner's (1976, pp. 67-69) study show that older female teenagers are more likely to begin contraceptive practices when they become sexually active than are younger women. Data charted on a graph by age at first intercourse and first use of contraception illustrates that about one-quarter of all girls under age 14 begin use of birth control in the same year that they begin having sexual relationships. Use within the first year increases with age: about three-quarters of the 17 year olds sampled begin use of a method the same year they begin intercourse, while slightly more than three-quarters of those over 18 do so. The authors further observe:

The gap between first intercourse and first use of contraception that was observed in 1971 has not narrowed significantly. Those who delay the use of contraception are much more likely than those who do not to have had a pregnancy" (p. 71).

Recent studies provide an overview of the age when teenagers begin to have sexual intercourse. Sorensen's (1973, p. 197) study found that of those teens who were sexually experienced, $13 \%$ began having sex at age 12 or under, $30 \%$ had their first experience at age 13 or 14 , and 
$37 \%$ at 15 or 16 . The remaining $20 \%$ initiated sexual activity at age 17 through 19. There were variations between males and females. More boys began sexual activity at earlier ages than girls. Finkel and Finkel (1975) found the mean age at first intercourse to be 12.8 years for the males of all ethnic groups in their sample. The range was 5 to 17 years, with white males beginning somewhat later than those of other ethnic groups. Arnold's (1972) study assessed the mean age of first intercourse for males in his study at 14.3 years, and their female partners at 14.6 years. Settlage et al. (1973) found that sexual activity for most of the girls in their study began between 15 and 16 years of age, while Zelnik and Kantner noted 16.2 years as the mean age at onset of intercourse for the sexually experienced young women in their study.

While these figures are not representative of teens who are not engaging in coitus, they do confirm the observations that teenagers who are sexually active may begin these activities at a relatively young ages, and are in need of contraceptive education and services which would involve both genders in the effort to prevent unwanted pregnancies. 


\section{PARTNER INELUENCE ON CONTRACEPTION}

In an interview with The Family Planner, Zilbergeld

(1977, pp. 9-I1) contends that "It takes two to make a baby and it helps if you've got two to prevent pregnancy. It just dosen't make any sense to ignore half of the population" (pp. 9-10).

It is zilbergeld's premise that men should be included in program efforts because partners interact with one another and these interactions affect contraceptive use:

Many agency people say that there's no sense involving men until there is a better type of male contraceptive. This kind of naive thinking, which confuses who's chiefly responsible for using the method with who ought to participate in contraceptive decision-making, would also have to change. We're dealing with human issues and problems--or at least we should be. A man who has something to say about the type of contraception used, and who knows that his partner has some conflicts about contraception, is in a much better position to support her and ensure that there aren't any unwanted pregnancies than a man who has had no involvement in the subject (p. 11).

A recent study submitted to the Department of Health, Education and Welfare (Note 2) found that over half the teens questioned at a clinic felt it was important for partners to accompany them to clinics. Additionally, "many of the teens interviewed said that their boyfriends were sources of support for their use of birth control, and in some cases the decision to use birth control was described as a mutual 
one" (p. 56).

Regardless of these attitudes, the study team noted that few boyfriends came to the clinic. Of these, most simply waited for their girlfriends. About 33\% were asked to take part in clinic classes with their partners. Most of the boys came because "their girlfriends asked them to" or "to provide transportation." The team noted that:

Most of the men responding to the questionnaire agreed that boyfriends should be included in family planning clinics, but only five out of the total 46 wanted to be included more. Less than half of the men felt completely comfortable being in a clinic, partly out of general embarassment and a sense that they didn't belong there. Many felt that more boyfriends didn't come because they thought clinics were oriented primarily to females (p. 57).

The study team noted the importance of including males

in the clinic process in the following manner:

Teens in the study indicated that they are influenced by their partners' feelings in their own use of birth control; these feelings are especially important when it comes to the use of condoms, spermicidal foams, diaphragms, rhythm and withdrawal. By not including boyfriends in the family planning process, clinics are ignoring an important influence on teenage women as effective contraceptors. Equally important, perhaps, they are lending support to the common notion that birth control is the woman's business (pp. 56-57).

Akpom et al. (1976) studied young women in a family planning clinic and found that while most were self-referred of influenced by people other than boyfriends, the boyfriends of $13 \%$ of the girls had influenced them to come to the clinic. The authors further note: 
It appears that the boyfriends felt some responsibility in preventing conception. In response to the question on the role of the boyfriend in the decision to practice contraception, $77 \%$ (208) of the respondents said that the boyfriend recommended or strongly recommended it, while three percent (9) said he was indifferent. Another $3 \%$ reported that the boyfriend opposed or strongly opposed contraception. No information was available from $17 \%$ (46) of the girls (p. 206).

Cooperation, or the lack of it, in respect to contraceptive use among working class marxied couples has been discussed by Rainwater (1960) who postulates that effective contraception is linked to mutuality in sexual relationships:

As might be expected, the sense of personal closeness and co-operation that goes with genital mutuality carries with it an openness in the discussion of family planning goals and effective co-operation in some method of contraception (p. 123).

The duality of successful contraception is described

by Rainwater in an earlier chapter in this manner:

Effective contraceptive action is made up of a series of separate, co-operative, and deliberate acts which involve both man and woman and which interfere with conception... The co-operative nature of contraceptive acts and the fact that they must be repeatedly performed if family limitation is to be achieved are of crucial importance in understanding couples' success or failure in carrying out their plans (p. 20).

He further discusses cases where a lack of cooperation on the part of one partner can sabotage the best of intentions, thus affecting effective use of contraception. Schofield's (1973, pp. 112-116) British study queried male and female respondents about the effect the method of 
contraception they employed had on their sexual enjoyment. More males than females felt contraception "spoilt" sex, while more women than men said it added to enjoyment. Most of the men and women using non-permanent male methods said they "spoilt" sex. While varying responses were noted for female methods, the author notes a "surprising" result regarding the pill. Nearly all the women said it added or made no difference to their enjoyment. Over $40 \%$ of the men said their wive's pill use "spoilt" their sexual pleasure. Schofield postulates several possible reasons for the high rate of "spoilt" rankings for so many men, among them, changes in female sexual desires as the result of the pill use, perceived dangers of taking pills, or uncertainty that the wife will follow the regimen of pills to prevent pregnancy, which limits the male "control" of the situation. Schofield writes:

But the most likely explanation for this attitude is that the man regards the pill as a threat to his dominant role. The man is usually the initiator of sexual intercourse (in his opinion, at any rate) and he fears that he will lose this initiative if it is the woman who is in control of contraception. Many people still think that birth control is the man's business. A quarter of all the men in this group said that it was the man's responsibility (p. 115).

Among Schofield's conclusions is the observation that "more time and money should be spent on persuading the man that contraception is acceptable, propitious, and necessary" (p. 116). 
Male partners have been shown to influence female contraceptive risk-taking (Luker, 1975; Morton-Williams \& Hindell, 1972, cited in Schofield, pp. 124-125), and to decide in favor of, or against, the use of a particular method, (Deys \& Potts, 1972, Morton-Williams \& Hindell, 1972, cited in Schofield, p. 124-125; Rainwater, 1960). Women also may influence male partners in risk-taking by their willingness to have intercourse sans protection (zilbergeld, 1975, p. 23).

Women also have been shown to influence the choice of method use. Studies note this to be true in the case of vasectomy. Mullen, Reynolds, Cignetti and Dornan (1973) studied respondents regarding attitudes about vasectomy. Among their findings they report that "a majority of the married respondents have discussed vasectomy with their spouses" (p. 333). They further note that wives may play an important role in the decision to have a vasectomy. Roberto (1973) offers similar conclusions. He states:

The wives of the clients appear to be more ready to talk about vasectomy than the husbands. They are usually the ones who inquire and make appointments for their husbands. Their previous position as the principle carrier of the responsibility of pregnancy predisposes them to be especially appreciative of the merits of vasectomy. Wives are an untapped set of motivators to who more communication should be addressed (p. 6).

The Iiterature demonstrates that both partners have an influence in contraceptive utilization. 


\section{THE EMERGENCE OF MALE PROGRAMS}

\section{AND SUMMARY}

In concluding the overview of the literature it is appropriate to briefly review some recent developments in male family planning programs, most of which are predicated on the issues discussed throughout the literature.

There is evidence of a growing cadre of professionals in the family planning field who are concerned with male involvement in family planning (Plopper, Varner, Wagman, 1975; The Family Planner, 1977), and male programs have been established in metropolitan areas across the country. Chicago Planned Parenthood has had a Male Motivation/Education program since 1971. Programs for males or programs involving both partners in the clinic process are operated by planned Parenthood Affiliates in many areas. In addition, Planned Parenthood agencies in varying locations conduct "rap sessions" which are geared to teenagers:

... agencies have tried to overcome the mostly female atmosphere of contraceptive clinics by encouraging patients to bring their boyfriends with them to the raps. Male participation tends to have a positive effect on the quality of the sessions, as it permits a dialogue between the sexes" (House \& Golsmith, 1972, p. 23).

County Health Departments are also instituting male programs. The City and County of San Francisco Department of Public Health opened the Men's Reproductive Health Clinic 
in 1976, and their sources indicate that other such clinics may be in operation. (Fact Sheet, The Men's Reproductive Health Clinic, Note 3). Several reasons for the existence of an all-male clinic have been outlined in the Fact sheet, among them, the need for medical services for men, counseling, the need for a clinic for men who wish to interact with women in family planning decisions, and the fact that many couples may be returning to methods other than the pill "... which depend on partner involvement and support for successful oontraception" (p. 3).

Summary

Several reasons for male involvement in the contraceptive decision-making process emerge from the literature. The involvement of partners in a mutual effort and the creation of a climate where partners discuss sexuality and method use could increase successful contraception. There are indications that men are willing to be involved, and their potential receptiveness should not be ignored. By the same token, those men who are resistent to contraception either for themselves or for their partners, or who have been socialized out of responsibility by the prevalence of female methods may be made more aware of the fact that birth control is a mutual responsibility by increased efforts at education and outreach. 
CHAPTER III

DESCRIPTION OF THE STUDY

\section{Objectives}

A primary objective of this exploratory study was to examine partner attitudes regarding birth control including: the male's attitudes toward his own involvement in birth control, his partner's attitudes and perceptions about his involvement, and in some cases a correlation between the two. A further objective was to ascertain the extent to which men desire such involvement. The study was not intended to test specific hypotheses but rather to obtain data for utilization, and upon which further research might be based.

\section{Instruments}

Two instruments were developed by the researchers to measure attitudes regarding male involvement in the decisionmaking process of obtaining and/or using birth control. Matched questionnaires with identical cover letters were designed for sexual partners, focusing on attitudes and bahavior regarding birth control and sexuality.

on both instruments the initial questions gathered 
demographic information. Most subsequent questions were either multiple choice or could be answered yes or no with a check mark. Additional comments were required on some. The final questions on both questionnaires were open-ended, asking for general comments and suggestions for improving the services at the Portland Planned Parenthood Clinic (hereafter referred to as PPP).

The men responded primarily about themselves. On some questions the women were asked to give their perception of their partner's attitudes. The matched questions differed only in gender direction, e.g.: "If condoms were less expensive, do you think you...?" for the men; and "If condoms were less expensive, do you think your.partner...?" for the women. There were 28 matched questions. Four additional questions were directed to the men only, e.g.: "How comfortable were you in the waiting room?"

\section{Pilot study}

A pilot study was conducted to test for clarity of the questions, respondents' understanding of terms used, and general utility of the format. Ten couples seated in the waiting room at PPP were randomly selected to complete the questionnaire. Based on the reactions, several changes were made. Further suggestions were solicited from the research committee of the Portland Planned Parenthood Board 
of Directors, and incorporated into the final instruments.

Population and sample

Portland Planned Parenthood:provides a variety of services related to family planning. The administrators of the clinic were interested in the possible utility of the study's findings. They agreed to cooperate with the researchers and to contribute support services. Any couple who came to PPP for services from september through December, 1977 became part of the population. The study was conducted during those clinic hours for which a researcher was available. An attempt was made to collect data from both day and evening clinic hours and from each day of the week. During those designated time periods couples were approached by an interviewer and asked to participate in the survey. An attempt was made to include every couple, with the exception of those who came for supplies only and were not required to wait for service.

\section{Data Collection}

One of the three researchers approached each couple in the clinic waiting room. She introduced herself, explained the nature of the study, and invited their participation (only one couple declined). Couples were asked not to discuss the questionnaire with each other while 
filling it. out, as this could bias their responses. Confidentiality was assured. They were instructed to seal the completed questionnaire in an envelope which was provided and place it in a box at the counter. The questionnaires were identified only by matching numbers in order to pair the responses. Fifty-five couples participated. Four of these matched questionnaires were rejected for lack of completion.

\section{Statistical Analysis}

Data from the completed questionnaires were coded, key punched on cards, and computer-analyzed. The initial print-out for male and female responses included tallies, means, and standard deviations for each question. These data were then used for analysis and comparison between the male and female responses. Responses from five questions were cross-tabulated pairwise to determine the extent of agreement or disagreement between the individual pairs. A Kappa test was run on these five cross-tabulations to determine the strength of the findings. This information is of value if the result is greater or less $(+$ or -2 than 64. Since our results did not exceed these limits, this information was not relevant and was not included. Two chi square tests were calculated to determine a possible correlation between selected questions. These findings are 
reported in the analysis of the data.

\section{Limitations of the Study}

A major limitation of this study was availability of subjects. The sample was limited by numbers and representation, due to the fact that the population was restricted to couples coming to the clinic. Consequently, the sample reflects a degree of bias. As a result, the findings can be generalized only to those people coming to PPP, and can not be applied to males or couples in general.

Finally, the questionnaire was somewhat limited in that a few of the questions appeared to be confusing to the respondents, which may have altered the results. For instance, responses indicated that men may have varied widely in their interpretations of the question about being "more involved in the decision-making process." Also, qualifiers to responses about consenting to sexual relations without birth control implied differing interpretations of that question's intent. 
CHAPTER IV

ANALYSIS OF THE DATA

DEMOGRAPHIC VARIABLES

Age, marriage and education all impact on sexual attitudes and related behavioral patterns. This demographic information was gathered in order to provide the reader with a general picture of the characteristics of this particular study sample.

Age

Fifth-one male/female pairs completed the questionnaire. Males ranged in age from 18 to 37 years with a mean age of 23 years; females ranged in age from 15 to 32 years with a mean age of 21 years. On the average, female respondents were 1.84 years younger than the males. (See Figure 1). Ongoing records maintained at Portland Planned Parenthood show that an overwhelming majority of women clients consistently fall in the age range of 20 to 24 years of age.

\section{Marital status and living arrangement}

Over half the respondents, $57 \%$ (29) of the males and $61 \%$ (31) of the females, had never been married; while 29\% (15) of the males and $27 \%$ (14) of the females were presently 
FIGURE I

AGE OF RESPONDENTS

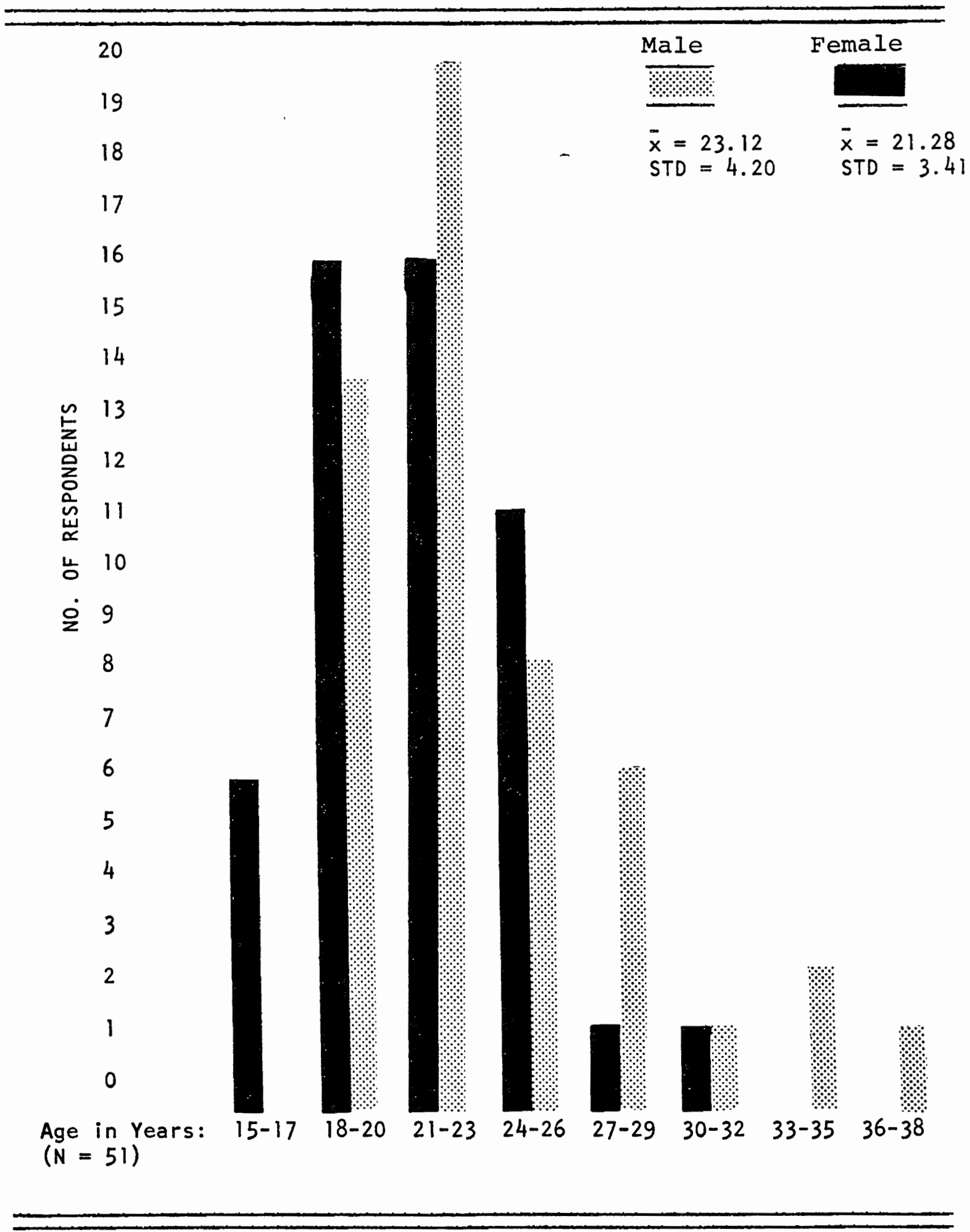


married. Concurrently, a majority of the couples were living with their sexual partners, $63 \%$ (32) of the males, 61\% (31) of the females. (See Tables I and II). All but TABLE I

PRESENT MARITAL, STATUS

\begin{tabular}{lrrrr}
\hline & MALE & PERCENT & FEMALE & PERCENT \\
\hline Married & 15 & 29 & 14 & 27 \\
Never Married & 29 & 57 & 31 & 61 \\
Separated & 0 & 0 & 1 & 2 \\
Divorced & 7 & 14 & 5 & 10 \\
TOTALS & 51 & 100 & 57 & 100 \\
& & & & \\
\hline
\end{tabular}

TABLE II

PRESENTLY LIVING WITH SEXUAL PARTNER

\begin{tabular}{lcccc}
\hline & MALE & PERCENT & FEMALE & PERCENT \\
\hline Yes & 32 & 63 & 31 & 61 \\
No & 19 & 37 & 20 & 39 \\
TOTALS & 51 & 100 & 51 & 100 \\
& & & & \\
\hline
\end{tabular}

one of the married couples were living together. In the case of the one couple, the man reported that he was married and living with his sex partner, and the woman said she was 
not married and not living with her sex partner. By subtracting the percentage of married from the percentage of those living with their partners, we find that those partners who were never married, separated or divorced but presently living together comprise $34 \%$ of the total population. (Men: $63 \%-29 \%=34 \%$; Women: $61 \%-27 \%=34 \%$ )

\section{$\underline{\text { Education }}$}

The educational level was roughly consistent with the age distribution. Because there were 6 females but no males under age 18, a higher rate of high school completion is to be expected from the males. Over half of the male population $51 \%$ (26), had finished high school having completed an average of 13.4 years; whereas $37 \%$ (19) of the females had completed high school with a mean 12.9 years in school. (See Figure 2). The women indicated greater aspirations to obtain higher education and finish college. (See Table III). 
FIGURE 2

\section{COMPLETED EDUCATION}

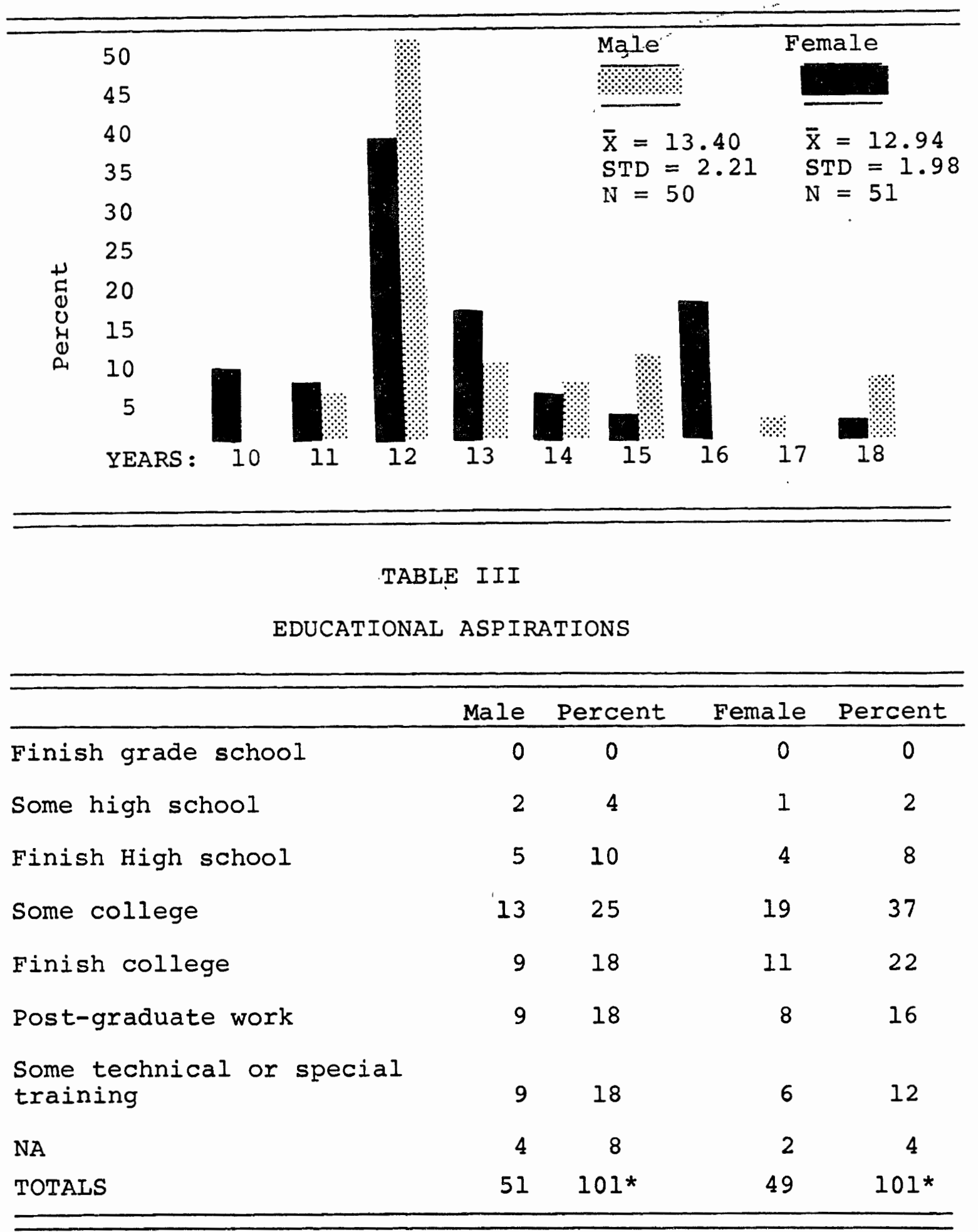

* percents do not equal 100 due to rounding. 


\section{MEN'S RELATIONSHIP. TO THE CLINIC}

It was important to learn why men came to Portland Planned Parenthood, since the services are generally considered to be for women only and male participation is minimally encouraged. Related questions inquired where the couple had obtained birth control before coming to the clinic, who initiated their visit, and how comfortable the man felt while waiting for the woman.

\section{Initiator of visit to Portland Planned Parenthood}

A cross-tabulation (see Table VXIII in Appendix) was computed between male and female respondents for the question, "Whose idea was it to come to Planned Parenthood?", in order to determine the extent of agreement or disagreement by the paired responses. It was found that 13 couples were in agreement that it was the female's idea; 14 couples agreed that it was a joint decision. In 8 of the couples, the male thought it was a joint idea while the partner believed she had had the original motivation. Three couples disagreed on this point in that the male thought it was a joint decision while the female said he had initiated the visit. By the same token in 7 paired responses the male stated it was her idea to come to Planned Parenthood while she believed they had both thought of it. Over half or $53 \%$ (27) of the respondents were in agreement with their partner on 
who first decided to visit to clinic.

This question was posed for multiple reasons. First, it implies motivation demonstrating who initiates or pursues the use of birth control. In this study it was overwhelmingly either the woman's or a joint idea. Second, it is one indicator of how the male views his involvement in the birth control process. Fifth-three percent (27) of the total male respondents saw it as a joint decision and $41 \%$ (21) reported that the woman had initiated the plan. (See Table IV). Similarly, it is one indicator of the female's view of her partner's involvement. Forth-five percent (23) of the female respondents stated that it was their idea to visit Planned Parenthood and 438 (22) said it was a joint idea. Six percent (3) indicated the man had first wanted to come. Third, the cross-tabulation gives a clue to the extent of each couple's communication and/or awareness of the other's attitudes regarding this subject.

TABLE IV

INITIATOR OF VISIT TO PORTLAND PLANNED

PARENTHOOD BY SEX

\begin{tabular}{lrrrr}
\hline & MALE & PERCENT & FEMALE & PERCENT \\
\hline Mostly Mine & 1 & 2 & 23 & 45 \\
Mostly My Partner's & 21 & 41 & 3 & 6 \\
Joint Decision & 27 & 53 & 22 & 43 \\
Other & 2 & 4 & 2 & 4 \\
NA & 0 & 0 & 1 & 2 \\
TOTAIS & 51 & 100 & 51 & 100 \\
\hline
\end{tabular}


Prior Obtainment of Birth Control

Both male and female were asked about prior means of obtaining birth control. (See Table V). Fifty-one percent (26) of the males responded that they "didn't obtain" any birth control. Concurrently, 55\% (28) of the females had not obtained any method previous. to this visit. This could imply most respondents were not on birth control and were visiting the clinic for the first time (or that they were using non-medical, non-mechanical methods, i.e. withdrawal, rhythm).

TABLE V

PRIOR OBTAINMENT OF BIRTH CONTROL

\begin{tabular}{lrccc}
\hline & MALE & PERCENT & FEMALE & PERCENT \\
\hline Friend & 2 & 4 & 0 & 0 \\
Drug store & 11 & 22 & 4 & 8 \\
Vending Machine & 2 & 4 & 1 & 2 \\
Brother or Sister & 0 & 0 & 0 & 0 \\
Parents & 0 & 0 & 0 & 0 \\
Private doctor & 5 & 10 & 13 & 25 \\
Didn't obtain & 26 & 51 & 28 & 55 \\
Other & 3 & 6 & 5 & 10 \\
NA & 2 & 4 & 0 & 0 \\
TOTALS & 57 & $101 *$ & 51 & 100 \\
*percent does not equal & 100 due to rounding & & \\
& & & \\
\hline
\end{tabular}


Twenty-five percent (13) of the females had obtained a method of birth control from a private doctor while only $10 \%$ (5) of the males had done so. Twenty-two percent (11) of the males and 88 (4) of the females obtained prior birth control from a drug store. No one had secured birth control from a "brother or sister" or a "parent." Two males and one female reported that they received their method from a vending machine. Two males said they had obtained it from a friend. Reason for coming to Portland Planned Parenthood (Men Only)

Male respondents were asked why they came to Planned Parenthood. There were six possible responses to the question, and the instructions permitted choice of more than one alternative. A total of 86 reasons were marked. Of this number, 39 came "to keep partner company" and "to provide transportation." Only 9 men reported coming "to get more information on birth control. The remaining 9 were either curious, wanted to make sure his partner came, or felt that she had made him come.

Reaction to Clinic Waiting Room (Men only)

Male respondents were asked how comfortable they were in the waiting room. Twenty-four percent (12) said they were "very comfortable;" 73\% (37) answered "comfortable"; two felt "uncomfortable"; and none reported feeling "very uncomfortable." 
This high level of favorable response must be considered in light of the work by McPhee, Zushman \& Joss (1975). Their research sought to measure patient satisfaction in community mental health centers. They concluded that, "despite the variety of measurement methods employed, patient satisfaction with service was found to be routinely high" (page 401). They postulated that a high rating could be expected from a patient who was receiving service and who expected to continue receiving service (page 402). Even though the men in PPP waiting rooms were not clients themselves, it is possible that they might reflect this tendency due to their close association with the service their partners were receiving. In other words, the men may not have been as comfortable as they reported. 


\section{INVOLVEMENT WITH BIRTH CONTROL}

The following grouping of questions sought to determine the extent of male involvement in birth control. Participants were asked whether or not they had discussed the subject with their partner, the degree of sharing in the decisionmaking process, who should be responsible for using the method, and whether or not men would want to receive more clinic services.

\section{Discussion of birth control}

Ninety-six percent (49) of the couples had discussed the use of birth control. Only one couple had not discussed it. This may appear obvious because their presence at the clinic would indicate that some form of discussion had already ensued. This does in fact bias the question but not to the extent that one would initially assume. The female could already have been using birth control when the relationship began and he was accompanying her to the clinic, without prior discussion, to continue her method. The one male that answered "no" to this question stated he assumed she was using birth control. The extent of discussion on birth control has not been measured here, so the degree of actual male participation is unknown. The fact that both of the partners agreed in all cases gives evidence to their perception of male involvement as positive. 
Felt involvement in decision-making

Both sexes responded overwhelmingly that they felt equally involved with their partners in making decisions regarding the use of a birth control method, $80 \%$ (41) of the males and 76\% (39) of the females gave this response (See Table VI). A cross-tabulation of this data revealed

TABLE VI

FELT INVOLVEMENT IN DECISION-MAKING

Male Percent Female Percent

Not at all

$0 \quad 0$

Equal with my partner

41

80

1

2

It's my partner's.

responsibility

12

36

Some

8

16

0

0

I make the decision

1

2

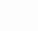

7

4

NA

0

0

2

14

TOTALS

$51 \quad 100$

49

100

that $65 \%$ (33) of the couples were in agreement (See Table XIX in Appendix). Six couples responded that the male felt "some" involvement while the partner felt "equal" involvement. Five couples responded that the male felt "equal" in the decision-making but the partner felt it was her decision. 
The greatest disparity among partners was noted for one couple in which the man indicated birth control was his decision while the woman felt she made the decisions about contraception.

Involvement in decision-making (Men only)

When male respondents were asked if they would like to be more involved in the decision-making process, 358 (18) said "yes", $49 \%$ (25) said "no", and 16\% (8) reported that the question was not applicable. Considering the high percentage of males who felt equally involved with their partners (See Table VI) a "no" or "not applicable" answered here may have indicated that the man already felt sufficiently involved.

Responsibility for birth control

Responses to the question, "whose responsibility do you think it ought to be to use birth control to prevent pregnancy," concurred with the previous findings. Eighty percent (41) of the males and $88 \%$ (45) of the females thought that men and women ought to share equally in the responsibility to prevent pregnancy (See Table VII). The cross-tabulation on these results revealed that $69 \%$ (35) of the couples agreed on this point. This was the highest level of agreement recorded. With nine couples, the women believed the responsibility should be equally shared 
TABLE VII

RESPONSIBILITY FOR BIRTH CONTROL

\section{Male Percent}

Mostly the man's

responsibility

Entirely the man's

responsibility

Mostly the woman's

responsibility

Entirely the woman's

responsibility

Equally the man's and

woman's responsibility

NA

TOTALS
0

0

6

3

41

1

51
0

0

12

6

80

2

100
Female

Percent 
A chi square test indicated there was no significant relationship between a man's desire to share the responsibility for birth control, and his desire to be more involved in birth control decision (see Table VXI in Appendix.)

Desire for clinic services (Males only)

The questionnaire for male participants explained that services offered to women at Portland Planned Parenthood included counseling, classes and physical examination. The man was asked if he would like to accompany her to any or all of those services, if it were possible and his partner agreed. The response was overwhelmingly affirmative, with counseling and classes the most popular. Seventy-eight percent (40) of the men responded "yes" for involvement in counseling, 75\% (38) for classes, and 61\% (31) wanted to be with their partner during the physical exam. 


\section{CHOICE OF METHODS}

Personal preference and partner reaction are factors influencing the effective use of birth control methods. Couples were asked which of the methods would not be accpetable to them. In particular, couple reaction to condoms was solicited.

Reaction to birth control methods

In companion questions, (see Tables VIII and IX) the

\section{TABLE VIII}
BIRTH CONTROL METHOD UNACCEPTABLE
TO RESPONDENT, RANKED

\begin{tabular}{llll}
\hline Ranking & Method & \multicolumn{2}{c}{ Number of Responses } \\
\hline 1 & Male & Female \\
2 & Fithdrawal & 42 & 41 \\
3 & Male sterilization & 36 & 37 \\
4 & Rhythm & 36 & 34 \\
5 & IUD & 25 & 25 \\
6 & Foam & 25 & 24 \\
7 & Foam \& Condom & 24 & 20 \\
8 & Condom & 21 & 15 \\
9 & Diaphragm & 17 & 17 \\
10 & Pill & 9 & 6 \\
& TOTALS & 275 & 253 \\
\hline
\end{tabular}


TABLE IX

BIRTH CONTROL METHOD PERCEIVED TO BE UNACCEPTABLE TO PARTNER, RANKED

\begin{tabular}{llll}
\hline Ranking & Method & \multicolumn{2}{c}{ Number of Responses } \\
\hline 1 & Male & Female \\
\hline 2.5 & Fernale Sterilization & 38 & 32 \\
2.5 & Withdrawal & 34 & 32 \\
4 & Rhyte Sterilization & 32 & 34 \\
6 & IUD & 28 & 32 \\
6 & Foam & 23 & 20 \\
6 & Foam \& Condom & 24 & 19 \\
8 & Condom & 21 & 22 \\
9 & Diaphragm & 21 & 18 \\
10 & Pill & 11 & 10 \\
& TOTALS & 8 & 7 \\
\hline
\end{tabular}

pairs were asked, (1) which methods of birth control they would not be willing to use or have their partner use; and (2) which methods they think their partner would be unwilling to use or have them use. These questions were posed to elicit any discrepancy between actual and perceived practice, which would be evidenced by sharply different responses. There was, however, a fairly close correlation between the male and female answers. By ranking according to number of responses we find little variation between the two. The fewer the responses, the more acceptable the 
method. For both questions contraceptive pills, were the most acceptable, followed by the diaphragm, condoms, and foam with condoms. Foam was preferred over the IUD. The four least acceptable methods included the two least reliable, rhythm and withdrawal and, interestingly, the two most reliable, male and female sterilization. Age of the respondents would be expected to be a factor in the rejection of sterilization as evidenced by the literature and corroborated here by unsolicited comments such as: "after we've had children" and "not at this time but at the proper time."

\section{Reaction to condoms}

Because the condom is generally considered a "male method" of birth control, it was singled out for specific inquiry. Those males who indicated an unwillingness to use a condom $(N=21)$ were asked to give their reasons. In a companion question, the females were asked if they and their partners ever use condoms and if not, why not. Thirtytwo answered "no". The reasons for non-use follow: "reduces sexual pleasure," males - 20, females - 16; "too much hassle," males - 10, females - 8; "do not think it is a successful method of birth control," males - 4, females - 11; "I would be embarrassed," males - 2, females - 0; "my partner did not want to," males - 4, females - 10, "other," males - 4, females - 10. This is similar to the literature which attributes to condoms, reduction of pleasure and inconvenience. Two and a half 
times as many females as males pointed to unwillingness of the partner. Almost three times as many females as males were unwilling to use the condom because they did not consider it a successful method (see Table X).

TABLE X

RESPONDENTS REASONS FOR CONDOM NON-USE

MALE

Reduces sexual pleasure

Too much hassle

Do not think it's a successful method

I would be embarrassed

My partner did not want to

Other

TOTALS
20

10

4

2

4

4

44
FEMALE

\section{6}

8

11

0

10

10

55

A follow-up question asked what the respondent's reaction might be if condoms were less expensive. A large majority indicated they would not use condoms even if they were cheaper (males - 36, females - 43, NA - 20). Two women and one man said they would either begin to use them or would use them more often if they were less expensive. The unusually large number of no answers may 
indicate that this question was difficult to answer. An interesting fact evolves when comparing this information to the question on perceived usage of a method. Condoms ranked third in popularity as a method they believed they would be willing to use, yet in actual practice most of the respondents reported they are not using condoms and do not plan to use them in the future regardless of price. 


\section{SEXUAL HISTORY}

It would appear to be evident that sexuality is integral to the use of contraception. Some practioners, however, place such emphasis on the medical and mechanical aspects of contraceptive methods that psycho-social factors influencing birth control use are given insufficient attention. Questions in the following section focus on attitudes toward sexual and contraceptive behavior, age at first intercourse and contraceptive use, and knowledge about sexuality.

Sexual knowledge

Male respondents were questioned regarding their knowledge about sex, pregnancy and birth control at the time of their first intercourse with their current partner. Female respondents were asked to rate their current partner's knowledge on the same scale (see Table XI). Sixty-four

\section{TABLE XI}

SEXUAL KNOWLEDGE AT FIRST INTERCOURSE

(MALE OF SELF, FEMALE OF PARTNER).

\begin{tabular}{lrrrr}
\hline & Male & Percent & Female & Percent \\
\hline Excellent/Very good & 14 & 27 & 20 & 39 \\
Good & 19 & 37 & 18 & 35 \\
Fair & 13 & 25 & 5 & 10 \\
Poor & 4 & 8 & 8 & 16 \\
NA & 1 & 2 & 0 & 0 \\
TOTALs & 51 & $99 *$ & 51 & 100 \\
\hline * percent does not equal 100 due to rounding & &
\end{tabular}


percent (33) of the males rated their knowledge as excellent to good, while $74 \%$ (38) of the women perceived their partner's knoweldge to be at that level. A fair to poor rating was given by $33 \%$ (17) of the males and $26 \%$ (13) of the females.

A follow-up question required the same rating regarding present knowledge, with males rating their own knowledge and females rating their partner's knowledge (see Table XII).

TABLE XII

PRESENT SEXUAL KNOWLEDGE

(MALE OF SELF, FEMALE OF PARTNER)

\begin{tabular}{lrrrr}
\hline & MALE & PERCENT & FEMALE & PERCENT \\
\hline Excellent/Very Good & 21 & 41 & 29 & 57 \\
Good & 24 & 47 & 19 & 37 \\
Fair & 6 & 12 & 1 & 2 \\
Poor & 0 & 0 & 1 & 2 \\
NA & 0 & 0 & 1 & 2 \\
TOTALS & 51 & 100 & 51 & 100 \\
& & & & \\
\hline
\end{tabular}

Findings reflect a similar pattern: "excellent" to "good" was checked by $88 \%$ (45) of the males and $94 \%$ (48) of the females. "Fair" was checked by $12 \%(6)$ of the men and $2 \%$ (I) of the women. There was a sharp drop in the "poor" rating, with no men and only one woman continuing to view 
their knowledge or their partner's knowledge as poor. It is evident then, that there is a difference in mens' perception of their knowledge of the topics and females' views of men's knowledge. More women saw their partners knowledge as "excellent" than did the men themselves. Furthermore, more men rated themselves as having a "fair" knowledge than did women. Whether the difference is due to participants' varying perceptions of the value of the terms is impossible to determine from the data. Perhaps these figures suggest the common social phenomenon in our culture that men know or should know more about these topics than they actually do.

A cross-tabulation of responses regarding present knowledge showed $53 \%$ (27) of the couples in agreement (see Table XXI in Appendix). Fifteen couples agreed on a rating of "excellent", and 12 couples agreed on "good". Differences of judgment included 10 pairs where a male judgment of "good" was matched by a female judgment of "excellent", and 5 pairs where the men thought their knowledge was excellent while their partners said "good." Overall, both sexes considered the degree of male knowledge in these areas to be quite high.

\section{Initiation of sexual intercourse}

Couples were asked "who generally takes the lead in having sexual intercourse?," on the assumption that assertion 
in the area of sexual relations might be related to behavioral patterns regarding birth control. The majority of individuals ( $56 \%$ or 57 respondents) stated that "either" of them took the lead in sexual intercourse. Of the remainder, $38 \%$ (39) reported that the male was the initiator, with only $6 \%$ (6) thinking the woman generally initiated sex. A cross-tabulation of paired responses revealed the following areas of agreement and disagreement (See Table XXII in Appendix) : 18 couples agreed that either took the lead; 9 couples agreed that the man generally took the lead; and 2 couples agreed the woman did. Among those who did not agree: 13 couples showed the men believing they took the lead while their partners thought they both led; for 7 couples, the women believed the male was leading while the men thought it was either of them. Paired responses were expecially important on this question, as they reveal possible clues to attitudes about sex-role interaction and communication.

Sexual intercourse without birth control

All respondents were asked if they would consent to sexual relations with their partner even if they were not using birth control. Twenty-seven percent (14) of the males and $24 \%$ (12) of the females said "yes", 33\% (17) men and $39 \%$ (20) women said "no", and men and women respondents equally to "sometimes" (37\% and $19 \%$ each). Male to female results were not shown to be significantly dependent (see 
chi square Table XVII in appendix).

Taken at face value these findings indicate a more cautious attitude on the part of the females, i.e., a greater desire to contracept. These findings must acknowledge inherent confusion interpretation of the question, however, as demonstrated by the following qualifiers: "I would consent to intercourse with my husband without birth control if need be again, but I don't need to (I'm on the pill)"; and a man's comment, "my partner uses it, not me." It is unknown whether those responding "sometimes" were considering those times when they wished to conceive as viable times to refrain from contraception, but considering the times they wishes to be protected from pregnancy as times to contracept.

\section{Peer Influence}

Because it has been demonstrated that behavior is significantly influenced by knowledge of the behavior of one's peers, according to spillane and Rysser (1975, page 67) the following inquiry was included in this study: "How many of your male (female) friends do you think are having sexual intercourse without using birth control?" Thirty-nine percent (20) of the males and $51 \%$ (26) of the females answered "just a few": $35 \%$ (18) males and 27\% (14) females said "some"; and $16 \%$ (8) of the males and $14 \%$ (7) of the females checked "quite a lot" (see Table XIII). 
TABLE XIII

PERCEPTION OF PEERS' PRACTICING SEXUAL INTERCOURSE WITHOUT BIRTH CONTROL

\begin{tabular}{lrccc}
\hline & MALE & PERCENT & FEMALE & PERCENT \\
\hline Just a few & 20 & 39 & 26 & 51 \\
Some & 18 & 35 & 14 & 27 \\
Quite a lot & 8 & 16 & 7 & 14 \\
NA & 5 & 10 & 4 & 8 \\
TOTALS & 51 & 100 & 51 & 100 \\
& & & & \\
\hline
\end{tabular}

These findings could indicate that the largest proportion of the respondents' friends practice birth control. The sizeable number of non-answers could suggest that the respondents were unaware of their friends' birth control practices because this topic was seldom discussed. The question was intended to disclose to what extent the clients thought that their friends were contracepting.

Age at first sexual intercourse

Figure 3 illustrates the age of the men and women in our sample at the time of first sexual intercourse. The largest number of respondents, 20 men and 20 women, initiated sexual activity at 16-17 years of age. Eleven females and 


\section{FIGURE 3}

AGE OF FIRST SEXUAL INTERCOURSE, IN YEARS

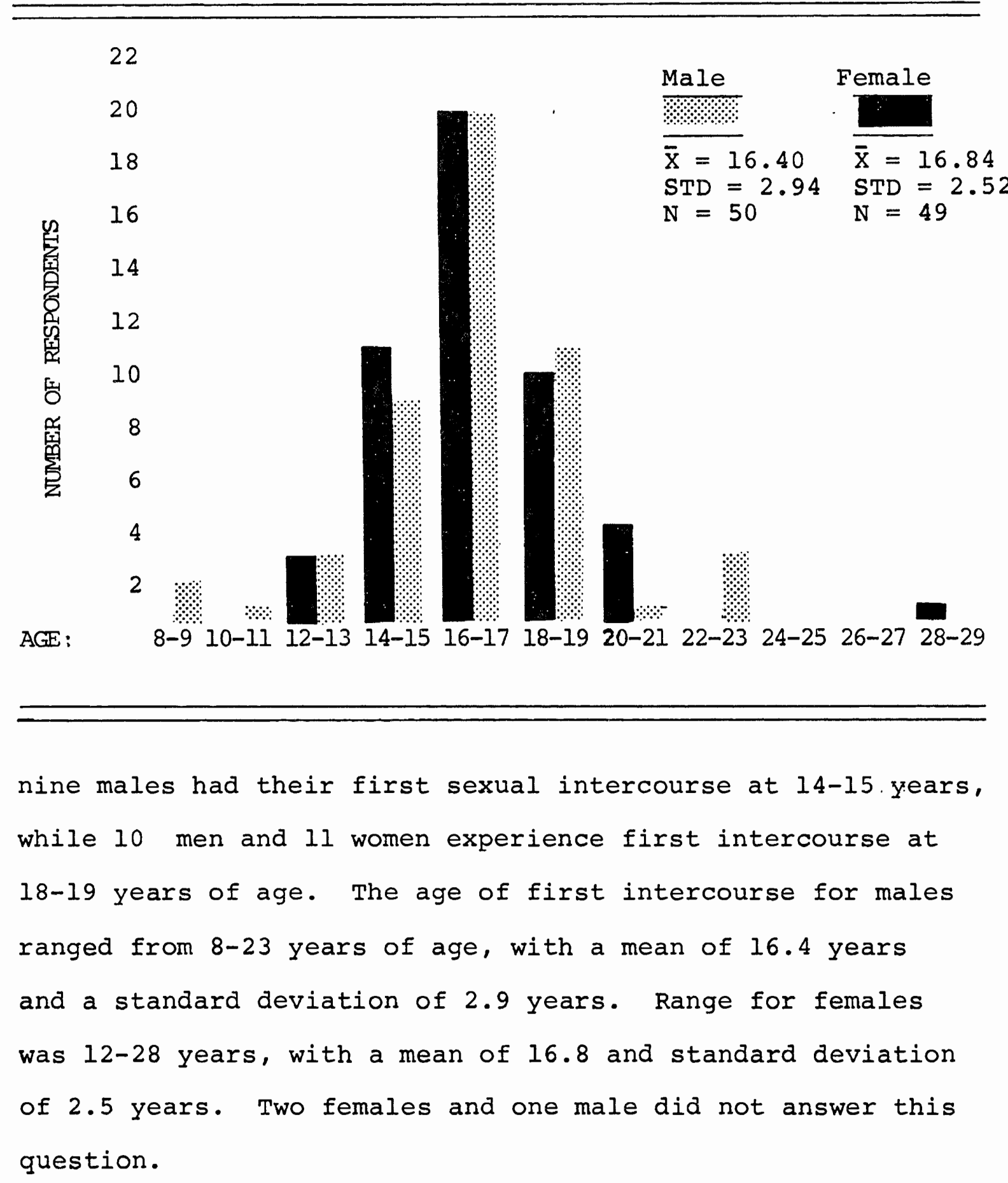


Age at first use of birth control

Males generally engaged in coitus earlier than females but initiated use of birth control at a later age. (see Figure 4). It is important to note the time lag between

FIGURE 4

AGE OF FIRST USE OF BIRTH CONTROL, IN YEARS

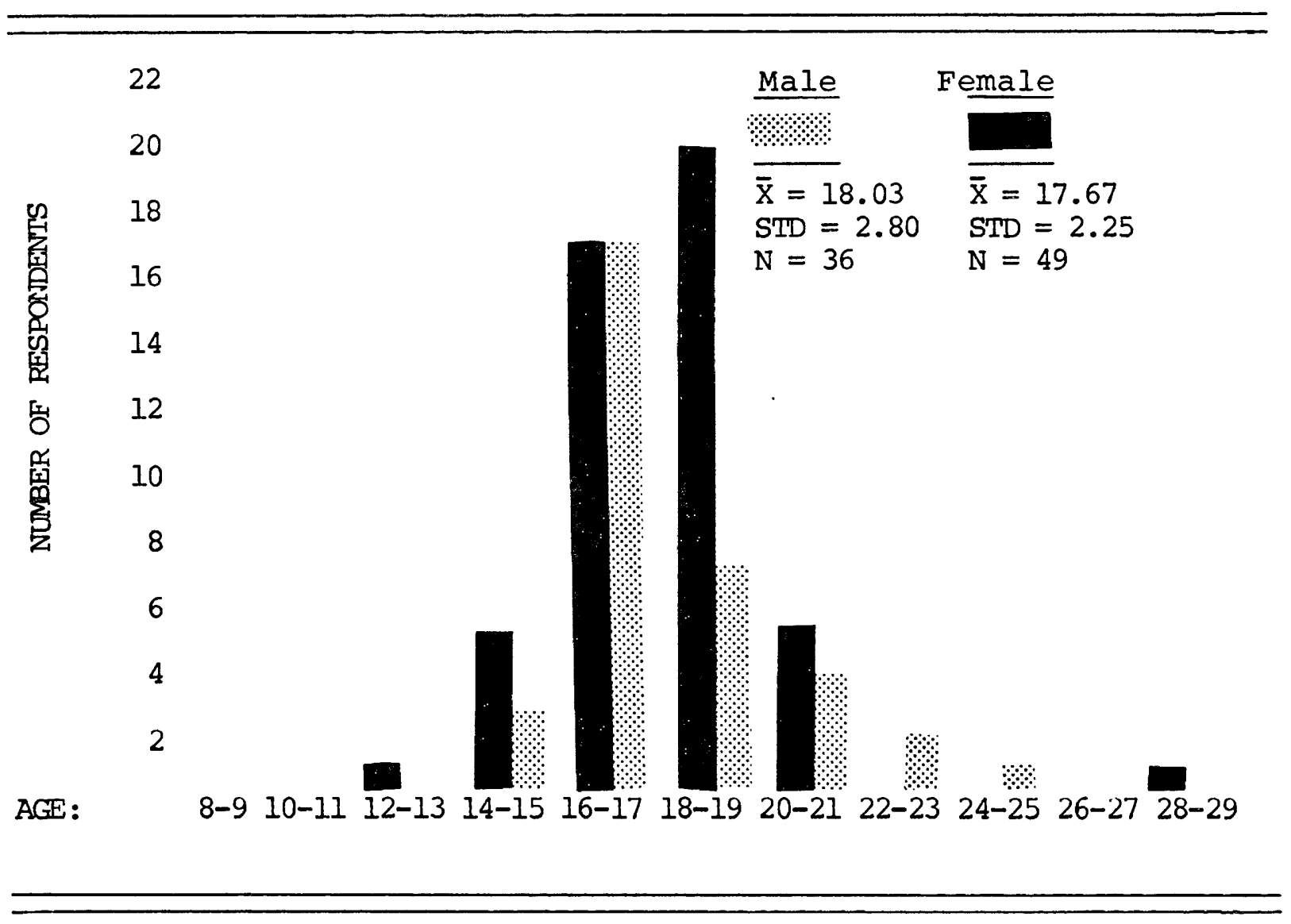


first intercourse and first use of birth control. For males, the mean for first birth control use was 18 years, showing a time lag of 1.6 years. There was a 6 year lag between the youngest first incidence of intercourse and earliest first use of birth control. This lag should be tempered, of course, by the presumption that intercourse at age 8 (earliest reported by a male) was probably not fertile. The mean for first birth control use for females was 17.7 years, giving a lag of .9 years. The females' lag between the youngest first intercourse and first use of birth control was one year. The majority of female respondents began utilizing a birth control method between 16-19 years of age. For male respondents the graph shows first contraceptive usage of 17 respondents began at ages 16-17, while 7 began at 18-19 years of age. The earliest contraceptive usage for females occured at age 12-13 and for males 14-15 years. Whereas all respondents had been engaging in intercourse at the time of this study, ten males and two females reported they were not yet using birth control.

These returns may reflect a possible confusion in phrasing of the questions about birth control (hypothetically, "no" may have been checked by a woman whose partner(s) had been using condoms, or by a man whose partner(s) had been using pills, IUD, diaphragm or foam. Similarly, clarification could alter the statistics on age of first use). As stated in the lit. review, Deys \& Potts (1972) address this confusion 
in use designation as it relates to the issues of involvement and responsibility.

Considering the above information it was not at all surprising, then, to find that 19 women had had an unplanned pregnancy, and 17 men had gotten a woman pregnant when they had not meant to. 


\section{INTEREST IN CLASSES}

The final grouping of questions attempted to elicit attitudes regarding willingness on the part of males to attend classes on birth control and sexuality if such were to be offered at the clinic. The males were asked to respond to the questions directly and the women were asked to give their perceptions of their partner's interest and/or possible involvement. In addition, women were asked to indicate whether or not they would like to have men attend such classes.

The majority of men had never attended classes of this kind: Fifty-eight percent (29) had never attended classes for birth control, $73 \%$ (36) and $83 \%$ (40) had never attended classes for female and male sexuality respectively. In a follow-up question for men only, 69\% (34) said they would like to know more about birth control. Of these 34 men, all but one indicated a willingness to attend a class. Fifty-three percent (25) expressed a willingness to attend a class on male sexuality, and an even greater number, $57 \%$ (28) would be willing to attend a class on female sexuality. Women's answers indicated a general lack of knowledge about their partner's previous class attendance. The large number of "don't know" answers suggest a lack of communication about the men's formal education regarding sexuality. The women's responses to the question asking for their perception 
of their partner's willingness to attend such classes, however, were remarkably close to the men's stated willingness to attend. This concurrence indicates a very good perception of current willingness of their men to be involved in sex education (:see Table XIV).

When asked if the men would prefer such classes or group sessions to be for men only or men and women attending together, the women's guesses of partner preference were fairly close to the men's actual choices. The majority of men, 57\% (28) wanted men and women to attend together, and for $25 \%$ (12) it would not make a difference. Only $6 \%$ of the men (3) thought the classes should be male only; $12 \%$ (6) said they wouldn't attend such classes anyway.

When the women were given the opportunity to indicate whether or not they would like partner attendance at classes, more women answered "yes" than "no". Forty-three percent (22) wanted their partners to attend a class on birth control, 37\% (19) wanted them to have a class on male sexuality and $49 \%$ (25) on female sexuality (see Table XV). The large number of "don't know" or "no answers" may indicate an' uncertainty or even ambivalence about inclusion of males as classes. It is possible that clarification in the question about whether the classes would be co-ed or for males only might have altered the responses. It is interesting to note, however, that the largest percentage (49\%) wanted their partners to know more about female sexuality. 
TABLE XIV

CLASS ATTENDANCE

\begin{tabular}{|c|c|c|c|c|c|c|c|c|c|c|}
\hline \multirow{3}{*}{ CLASSES } & \multicolumn{2}{|c|}{ MINLE } & \multicolumn{3}{|c|}{ FEMALE } & & & \multicolumn{3}{|c|}{ FEMALE } \\
\hline & \multicolumn{2}{|c|}{$\begin{array}{l}\text { PFEVIOUS } \\
\text { CLASS } \\
\text { ATIENDANCE } \\
\end{array}$} & \multicolumn{3}{|c|}{$\begin{array}{l}\text { PARINER'S KNOWLEDGE OF } \\
\text { PIREVIOUS CIASS } \\
\text { ATTENDANCE }\end{array}$} & \multicolumn{2}{|c|}{$\begin{array}{l}\text { WILUTNGNESS TO } \\
\text { ATTEND } \\
\text { CIASSES }\end{array}$} & \multicolumn{3}{|c|}{$\begin{array}{l}\text { PERCEPTION OF PARINER'S } \\
\text { WILIINMENESS TO } \\
\text { ATTEND CILASSES }\end{array}$} \\
\hline & Yes & No & Yes & No & $\begin{array}{l}\text { Don't } \\
\text { know }\end{array}$ & Yes & No & Yes & No & $\begin{array}{l}\text { Don't } \\
\text { Know }\end{array}$ \\
\hline $\begin{array}{l}\text { Birth } \\
\text { Control }\end{array}$ & $\begin{array}{r}21 \\
(428) \\
N=\end{array}$ & $\begin{array}{l}29 \\
(588)\end{array}$ & $\begin{array}{l}13 \\
(268)\end{array}$ & $\begin{array}{l}21 \\
(418) \\
N=51\end{array}$ & $\begin{array}{l}17 \\
(338)\end{array}$ & $\begin{array}{r}33 \\
(678) \\
N\end{array}$ & $\begin{array}{c}16 \\
(338) \\
*\end{array}$ & $\begin{array}{l}29 \\
(588)\end{array}$ & $\begin{array}{c}8 \\
(168) \\
N=50^{*}\end{array}$ & $\begin{array}{l}13 \\
(268)\end{array}$ \\
\hline $\begin{array}{c}\text { Male } \\
\text { Sexuality }\end{array}$ & $\begin{array}{l}13 \\
(278) \\
N\end{array}$ & $\begin{array}{l}36 \\
(738) \\
*\end{array}$ & $\begin{array}{c}5 \\
(108)\end{array}$ & $\begin{array}{l}21 \\
(418) \\
N=51\end{array}$ & $\begin{array}{l}25 \\
(498)\end{array}$ & $\begin{array}{l}25 \\
(538)\end{array}$ & $\begin{array}{l}22 \\
(478)\end{array}$ & $\begin{array}{l}27 \\
(558) \\
N=\end{array}$ & $\begin{array}{l}12 \\
(258) \\
+\quad N A=\end{array}$ & $\begin{array}{l}10 \\
(208)\end{array}$ \\
\hline $\begin{array}{c}\text { Female } \\
\text { Sexuality }\end{array}$ & $\begin{array}{c}8 \\
(178)\end{array}$ & $\begin{array}{l}40 \\
(838)\end{array}$ & $\begin{array}{l}4 \\
(88)\end{array}$ & $\begin{array}{l}21 \\
(418) \\
N=51\end{array}$ & $\begin{array}{l}26 \\
(518)\end{array}$ & $\begin{array}{l}28 \\
(578)\end{array}$ & $\begin{array}{r}21 \\
1438\end{array}$ & $\begin{array}{l}26 \\
(538)\end{array}$ & $\begin{array}{l}12 \\
(258) \\
N=49 *\end{array}$ & $\begin{array}{l}11 \\
(228)\end{array}$ \\
\hline
\end{tabular}

${ }^{*} N$ not equal to 51 due to non-responses 
TABLE XV

WOMEN'S PREFERENCE FOR PARTNER

TO ATTEND OR NOT TO ATTEND CLASSES

\begin{tabular}{|c|c|c|c|c|}
\hline \multicolumn{5}{|c|}{ RESPONSES } \\
\hline Classes & Yes & No & Don't know & No Answer \\
\hline $\begin{array}{l}\text { Birth } \\
\text { Control }\end{array}$ & $\begin{array}{c}22 \\
(438)\end{array}$ & $\begin{array}{c}16 \\
(318)\end{array}$ & $\begin{array}{c}9 \\
(188)\end{array}$ & $\begin{array}{c}4 \\
(88)\end{array}$ \\
\hline $\begin{array}{l}\text { Male } \\
\text { Sexuality }\end{array}$ & $\begin{array}{c}19 \\
(378)\end{array}$ & $\begin{array}{l}15 \\
(298)\end{array}$ & 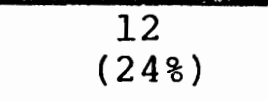 & $\begin{array}{c}5 \\
(10 \%)\end{array}$ \\
\hline $\begin{array}{l}\text { Female } \\
\text { Sexuality }\end{array}$ & $\begin{array}{c}25 \\
(498)\end{array}$ & $\begin{array}{l}12 \\
(24 \%)\end{array}$ & $\begin{array}{l}11 \\
(228)\end{array}$ & $\begin{array}{l}3 \\
(68)\end{array}$ \\
\hline
\end{tabular}




\section{ADDITIONAL COMMENTS}

The two concluding questions were open-ended to allow a free expression of reactions not covered by the previous responses. Respondents were asked to be as specific as possible in giving suggestions for improvement of services for men at the agency. Finally, they were given the opportunity to add any comments they wished to make.

The responses offered by 29 males and 26 females fall into four basic categories:

1. Favorable comments regarding the services provided. Thirteen males and 13 females offered favorable comments about the clinic.

2. Unfavorable comments about service delivery. Three men and 3 women had negative reactions to the services. Two of those men complained about the long wait or scheduling problems; and another man said the clinic needs more male help. One woman did not like to have to fill out the green form at each visit; another observed that men feel uncomfortable because the clinic is "mostly for the female"; and a third stated that she is made to feel stupid and guilty for having fears instead of being reassured.

3. Comments relating to male inclusion in the clinic services. Eight men and 13 women felt there 
3. (Continued)

should be an added effort to include men in the whole clinic's procedure, e.g., exams, classes, and diaphragm insertion. One man wanted more male clinic personnel, and another suggested more male oriented literature in the waiting room. Seven men and 5 women were not sufficiently aware of male services to be able to make an informed statement.

4. Comments relating to male methods of birth control Four men and 6 women wanted improved male methods and/or more information about male alternatives. Three respondents expressed a desire for a male birth control pill, 2 wanted a reversible vasectomy and 2 men asked for better "rubbers." One woman thought the "field of male contraceptives needs to be broadened so that it can take some of the burden off of women." (See Appendices C\&D for verbatim responses.) 


\section{CHAPTER V}

\section{CONCLUSIONS AND RECOMMENDATIONS}

The emphasis of this research is on male involvement in family planning. With the advent of the birth control pill and the I.U.D, the responsibility for contraception was directed to the woman. Both the literature and the findings of this study indicate that some men desire more involvement and shared responsibility in decision-making and use of contraception. The majority of male respondents in this study reported feeling that they should equally share the responsibility for birth control, but in general, family planning clinics have been excluding men in their clinic procedures and outreach contributing to the prevalent notion that birth control is a female concern. The researchers, as well as many of the authors on the subject, maintain that inclusion of males in birth control decisionmaking and sexuality education is necessary to reduce unplanned pregnancies, and is also the right of every man involved.

The recommendations that have evolved out of this research study are aimed at reversing the tendency to view birth control as a female domain, and to stress a climate 
of shared responsibility between sexual partners. The objective of these recommendations are to suggest clinic changes for increased involvement of men who presently indicate such a desire, and to advocate accelerated educational outreach to stimulate partner awareness of the advantages of male involvement.

Educational endeavors are extremely important in attracting male interest. Content and phrasing of messages in speeches and media releases can stress partnership in contraceptive use. Male modeling is important. Male radio and television announcers can inform the public that men are welcome at the clinic and that services are available for both men and women. More male speakers might be recruited (perhaps from such groups as the Men's Resource Center) so that educational outreach can be offered by male/ female teams. Birth control-sexuality talks can be offered to all-male groups, such as the Boy Scouts, YMCA, correctional facilities, fraternities, etc.

A major challenge is to eliminate, or at least shorten, the lag between onset of first intercourse and first use of effective contraception. The degree of this challenge is evidenced by the study's findings that 35\% of the respondents had been involved in an unplanned pregnancy. Males began engaging in sexual intercourse earlier than females, but began employing birth control later. Over 
half the respondents had not used any contraceptive method before coming to Portland Planned Parenthood; but of those who did, the drugstore was the most common source of obtainment for males, suggesting the condom as the method of first use for them. Even though all of our respondents had engaged in sexual intercourse, 10 males and 2 women had never used birth control. These findings, which are similar to those found in the literature, strongly suggest a need for greater emphasis on outreach to young males, and a need for condom advocacy for this age group. (i.e., Among the very young, if contraception is used it is apt to be a non-perscriptive or over-the-counter method, and to be used by the male.)

The majority of participants in this study were 20 to 24 years of age and were partners in a stable relationship. Most of the men said they came to the clinic to keep their partner company or to provide transportation. A very small percentage came in order to get more information on birth control. From this, and comments offered by both sexes, it is clear that the men do not know what services are available to them and therefore do not see the clinic as a source of information or services regarding their own sexual needs. An initial clinic outreach, then, would be at the first telephone contact. The appointment clerk could stress that the man is welcome and could invite 
him to join the woman at the class and interview. A large proportion of men sampled expressed a willingness to accompany their partner to counseling (78\%) and classes (75\%). Several respondents commented on a need for a more male-oriented atmosphere in the reception and waiting areas. Even though most of the men in the study reported feeling comfortable there, several respondents commented on a need for more visible indications in these areas that birth control is also a man's business. They suggested that more men need to work at the front desk. Either volunteers or paid staff could be utilized in this position. Male-oriented posters, and informational literature, brochures, pamphlets, books, and magazines could further illustrate male involvement.

The intake form that is filled out with every clinic appointment could have a question asking whether the client would like to have her partner accompany her to the interview, class and exam. This would not only be effective in suggesting male inclusion to females that had not brought their partners with them, but also emphasize female choice in the matter.

The study found a willingness on the part of both men and women for male inclusion in clinic classes. Communication and discussion of birth control between partners should be emphasized at the classes. The study 
revealed that a high percentage (96\%) of the population had discussed the issue of birth control. The content of those discussions or whether there was disagreement over method choice, however, is not known. Therefore, having both partners present at the class ans subsequent interview provides an added assurance that questions can be fully answered regarding method use, and the dangers and reliability assigned to each method. Partner involvement in decision-making can maximize cooperation, increasing use effectiveness and continuation rate. Respondents tended to view the condom as an unreliable method and too much hassle to use. This concept can be altered by stressing its use with foam, and making the application of both methods a part of erotic love-making. The condom can then be seen as a more pleasurable (and reliable) experience, and enables the man to participate experientially in contraception. Even though many respondents indicated a distaste for condom use, they ranked it as the third most acceptable method, preceded only by the pill and the diaphragm. This contradiction was also reported in the literature, suggesting a willingness to forego some pleasure and convenience for an assurance of safe sex.

The classes could be video-taped to insure reliability and standarization, with a male/female team presenting information germane to both sexes. The men in classes 
could be taught to do breast exams for their partners, again emphasizing couple sharing and a fusion of need and pleasure.

At the subsequent interview the couple can ask any questions that might not have been answered in class or those that relate to them personally. They could be referred to a counselor for discussion relating to sexuality and/or sex roles if the couple so desire. Pregnancy counselors should be encouraged to include the woman's partner when providing the patient with the results of her test, and to consider them both as targets of concern. The man is often left sitting in the waiting room. (He may be just as worried or excited about the results as she is.) The literature discusses the concept that both partners "get pregnant," not just the woman. The responsibility must be shared.

Many of the men in the study expressed a desire to be present during their partner's exam. Implementing male inclusion would help to erase the sense of mystery many men feel regarding a "pelvic and pap." Men could be taught to insert the diaphragm and check its position to insure reliability. They would then be able to take a more active part and provide added assurance that the diaphragm does not get left in the dresser drawer during intercourse. Male cooperation has also been shown to 
favorably affect correct and continued oral contraceptive use.

A large number of men reported a desire to attend group sessions relating to birth control (67\%), male sexuality (53\%), and female sexuality (57\%), with the latter receiving the most interest. The study shows that women thought men knew more about birth control and sexuality than the men perceived themsevles as knowing. Society has cast the male as the more knowledgeable in the world of sex, yet few opportunities are afforded him to obtain accurate, detailed information about sexuality, particularly female sexuality. Society has also pressured the male to assume the role as primary sexual initiator, as reflected by the findings. As the double standard diminishes, and sex-role expectations shift to a more egalitarian balance, the need for communication sharply increases. While women do not necessarily wish to shift control over decision-making to men, they are indicating that they want increased involvement by their sex partners. Comments by female respondents called for a sharing of responsible contraception; they resent carrying the bulk of the burden.

Discussion groups can serve to promote a reassessment of attitudes, for both the individual and between partners. Such sharing can also increase attendees awareness of peer 
practices, which can influence behavior shifts. This is especially important for teenagers; and teens themselves can be effective peer educators. Again, members of the Men's Resource Center might be a valuable source of volunteers to help guide rap groups.

More men might find it possible to participate in clinic procedures if the schedule were adjusted to include some evening and Saturday morning hours.

Most of the above recommendations could be implemented in a short period of time. Two long range goals that might be considered are: I) the development of a male V.D. screening service, and 2) the implementation of a roving birth control and information clinic that increases access by taking the service to the men in their own locale or places where they congregate.

The researchers conclude, therefore, that men need to be socialized to an increasing acceptance of responsibility so that sexual partners can assume shared roles in sexual and contraceptive behavior. Family planning clinics can play a significant role in this process. 


\section{REFERENCE LIST}

Akpom, C.A., Akpom, K.I., \& Davis, M. Prior sexual behavior of teen-agers attending rap sessions for the first time. Family Planning Perspectives, 1976, 8 (4), 203-206.

Arnold, C.B. The sexual behavior of inner city adolescent condom users. The Journal of Sex Research, 1972, 8 (4), 298-309.

Arnold, C.B. A condom distribution program for adolescent males. In D. V. McCalister, V. Thiessen, \& M. McDermott (Eds.), Readings in family planning - A challenge to the health professions. St Louis: The C. V. Mosby Co., 1973.

Arnold, C.B., \& Cogswell, B.E. A condom distribution program for adolescents: The findings of a feasibility study. American Journal of Public Health, 1971, 61, 739-750.

Balswick, J. O. Attitudes of lower class males toward taking a male birth control pill. The Family Coordinator, $1972,21,195-201$.

Barber, D. Unmarried fathers: London: Hutchinson of London, 1975.

Bremner, W. J., \& dekretser, D.M. The prospects for new reversible male contraceptives. The New England Journal of Medicine, 1976,295 (20), $1111-1117$.

Byrne, D. A pregnant pause in the sexual revolution. Psychology Today, July 1977, pp. 67-68.

Cartwright, A. Parents and family planning services. New York: Atherton Press, 1970.

Darrow W. W. Attitudes toward condom use and the acceptance of venereal disease prophylactics. In M. H. Redford, G. W. Duncan, \& D. J. Prager (Eds.), The condom: Increasing utilization in the United states. San Francisco Press, Inc., 1974.

Deys, C. M., \& Potts, D. M. Condoms and things. In G. Raspe (Ed.), Advances in the biosciences: Schering workshop on contraception: The masculine gender. Vieweg: Pergamon Press, 1972. 


\section{REFERENCE IIST (continued)}

Deys, C.M., \& Potts, M. Factors affecting patient motivation. In J. J. Sciarra, C. Markland, \& J. J. Speidel (Eds.), Control of Male fertility. Hagerstown, Maryland: Harper \& Row, 1975 .

Finkel, M. I. \& Finkel, D. J. Sexual and contraceptive knowledge, attitudes, and behavior of male adolescents. Family Planning Perspectives, 1975,7 (6), 256-260.

Free, M. J., \& Alexander, N. J. Male contraception without prescription. Public Health Reports., 1976, 9 I (5), $437-445$.

Freedman, R., Whelpton, P. K. \& Campbell, A. A. Family planning, sterility and population growth. New York: McGraw-Hill, 1959.

Fujita, B. N., Wagner, N. N., \& Pion, R. J. Contraceptive use among single college students. In D. V. McCalister, V. Thiessen, \& M. MCDermott (Eds.), Readings in family planning - A challenge to the health professions. St. Louis: The C. V. Mosby Co., 1973.

Furstenberg, F., Jr., Gordis, L., \& Markowitz, M. Birth control knowledge and attitudes among unmarried pregnant adolescents: A preliminary report. Journal of Marriage and the Family, 1969, 31, 34-42.

Gilbert, R., \& Mathews, V. G. Young males' attitudes toward condom use. In M. H. Redford, G. W. Duncan, \& D. J. Prager (Eds.), The condom: Increasing utilization in the United States. San Francisco: The San Francisco Press, Inc., 1974 .

Guttmacher, A. F., Best, W., \& Jaffe, F. S. Birth control and love: The complete guide to contraception and fertility (2nd rev. ed.), London: The Macmillan Co., Collier-Macmillan Lta., 1969.

Harvey, P. D. Condoms in America. In M. H. Redford, G. W. Duncan, \& D. J. Prager (Eds.), The condom: Increasing utilization in the United States. San Francisco: The San Francisco Press, Inc., 1974.

Himes, N. E. Medical history of contraception. New York: Gamut Press, Inc., 1963. 
REFERENCE LIST (continued)

House, E. A., \& Goldsmith, S. Planned parenthood services for the young teenager. Family Planning Perspectives, $1972, \underline{4}(2), 27-31$.

Kantner, J. F., \& Zelnik, M. Contraception and pregnancy: Experience of young unmarried women in the united States. Family Planning Perspectives, 1973, 5 (1), $21-35$.

Kirkendall, I. A. Premarital intercourse and interpersonal relationships. New York: The Julian Press, Inc, 1961.

Lane, M. E. Contraception for adolescents. Family Planning Perspectives, 1973, 5 (I), 19-20.

Lewy, R. Male contraception. American Family Physician, 1977,15 (6), 107-109.

Lindeman, C. Birth control and unmarried young women. New York: Springer Publishing Co., 1974.

Luker $K$. Taking chances: Abortion and the decision not to contracept. Berkeley: University of California Press, 1975.

McPhee, C. B., Zusman, J. \& Joss, R. H. Measurement of patient satisfaction: A survey of practices in community mental health centers. Comprehensive Psychiatry, 1975, 16, 399-404.

Mullen, P., Reynolds, R., Cignetti, P. \& Dornan, D. A vasectomy education program: Implications from survey data. The Family Coordinator, 1973, 22 (3), 331-338.

Plopper, S., Varner, S., \& Wagman, E. (Eds.) The male role in family planning. Los Angeles-San Francisco: California Department of Health/Planned Parenthood, Alameda-San Francisco, Sacramento, June, 1975.

Rainwater, L. And the poor get children. Chicago: Quadrangle Books, 1960.

Reichelt, P. A., \& Werley, H. H. Contraception, abortion and venereal disease: Teenagers' knowledge and the effect of education. Family Planning Perspectives, $1975, \underline{7}(2), 83-88$. 
REFERENCE LIST (continued)

Roberto, E.I. Vasectomy responses. Family Planning Perspectives, 1973,5 (1), 5-6.

Scales, P. Males and morals: Teenage contraceptive behavior amid the double standard. The Family Coordinator, 1977, 26, (3), 211-222.

Schofield, M. The sexual behavior of young adults. Boston: Little, Brown, and Co., 1973.

Settlage, D.S.F., Baroff, S., \& Cooper, D. Sexual experience of younger teenage girls seeking contraceptive assistance for the first time. Family Planning Perspectives, 1973,5 (4), 223-226.

Sorensen, R. C. Adolescent sexuality in contemporary America. New York: World Publishing Co., 1973.

Spillane, W., \& Ryser, P.E. Male fertility survey: Fertility knowledge, attitudes and practices of married men. Cambridge, Mass.: Ballinger Publishing Co. , 1975.

The Alan Guttacher Instutute. Organized family planning services in the United States: FY 1975. Family Planning Perspectives, $1976, \underline{8}$ (6), 269-274.

The psychology of male (non) involvement. The Family Planner, $1977,8(2 / 3), 9-11$.

U. S. Bureau of the Census. Fertility indicators: 1970 . Current Population Reports (Series p.-23, No. 36). Washington D.C.: U.S. Government Printing office, 1971.

Veerhusen P.G. The role of the condom in planned parenthood programs. In M. H. Redford, G. W. Duncan, \& D. J. Prager (Eds.), The condom: Increasing utilization in the United States. San Francisco: The San Francisco Press, Inc., 1974.

Westoff, C. F., \& Jones, E. F. Contraception and sterilization in the United States, 1965-1975. Family Planning Perspectives, 1977, 9 (4), 153-157. 
Westoff, C. F., \& Ryder, N.B. United States: Methods of fertility control, 1955, 1960, \& 1965. In D. V. McCalister, V. Thiessen, \& M. McDermott (Eds.), Readings in family planning: A challenge to the health professions. St Louis: The C. V. Mosby Co., 1973.

Women's Health Care collective. Our bodies, ourselves, a book by and for women (2nd ed.) New York: Simon \& Schuster, 1976 .

Zelnik, M., \& Kantner J. F. Sexual and contraceptive experience of young unmarried women in the United States, 1976 and 1971. Family Planning Perspectives, $1977,9(2), 55-71$.

Zilbergeld, B. Men's views of family planning. In $S$. Plopper, S. Varner, \& E. Wagman (Fds.) The male role in family planning. Los Angeles-San Francisco: California Department of Health/Planned Parenthood Alameda-San Francisco, Sacramento, June, 1975. 


\section{REFERENCE NOTES}

1. Hale, D., Vadies, E., \& Fryer, M.A. Attitudes of adolescent males toward abortion, contraception and sexuality. Planned Parenthood Association/Chicago Area, Chicago, Illinois, mimeograph, undated, (1977).

2. Improving family planning services for teenagers. Final report. Submitted by Urban and Rural Systems Associates, Pier 1-1/2, San Francisco, California 94111, to Office of the Assistant Secretary for Planning and Education/Health, Department of Health, Education and Welfare, Contract HEW-05-74-304, June, 1976.

3. Fact sheet. Men's Reproductive Health Clinic, Family Planning Program, Health Center 4, City and County of San Francisco, Department of Public Health, 101 Grove Street, San Francisco, California 94102, 1977.

4. Six hints for developing your male education program. Planned Parenthood - Chicago's Male Motivation/ Education Program, 55 East Jackson Blvd., 20th Floor, Chicago, Illinois 60604, pamphlet, undated. 


\section{BIBLIOGRAPHY}

\section{ADDITIONAI SUGGESTED READINGS}

Bednarik, Karl. The Male in Crisis. New York: Alfred A. Knopf, 1970.

de Kretser, D. M. "Towards a Pill for Men." proceedings of the Royal Society of London 195, December 10, 1976): $161-174$.

Harvey, Philip D. "Condoms - A New Look." Family Planning Perspectives 4 (October 1972): $\overline{27-30}$.

Kinsey, Alfred C., Pomeroy, Wardell B., and Martin, Clyde E. Sexual Behavior in the Human Male. Philadelphia:

W. B. Saunders Co., 1948 .

Needle, R. H. "Factors Affecting Contraceptive Practices of High School and College-Age Students." Journal of School Health 47 (6) (1977): 340-345.

Okada, I. M., and Gillespie, D.G. "The Impact of Family Planning Programs on Unplanned Prenancies." Family Planning Perspectives 9 (July/August 1977): $173-176$.

Pannor, Reuben. "The Forgotten Man." Nursing Outlook 18 (November 1970): $36-37$.

Rosenfeld, Albert. "Controls on Male Fertility Now Seem Within Our Reach." Smithsonian Magazine, July 1977: $37-42$.

Sandberg, Eugene C., and Jacobs, Ralph I. "Rejection of Contraception." American Journal of Obstetrics and Gynecology 110 (1971): 227-242.

Scales, Peter, Etelis, Robyn, and Levitz, Norman. "Male Involvement in Contraceptive Decision Making: The Role of Birth Control Counselors." Journal of Community Health 3 (Fall 1977): 54-60.

Shah, Farida, Zelnik, Melvin, and Kantner, John F. "Unprotected Intercourse Among Unwed Teenagers." Family Planning Perspectives 7 (January/February 1975): $39-44$. 
Bibliography (continued)

Udry, J. Richard. The Social Context of Marriage. Philadelphia: J. B. Lippincott Co., 1974.

Wagner, Nathaniel N.,Fujita, Byron N., and Pion, Ronald. "Sexual Behavior in High School: Data on a Small Sample." Journal of Sex Research 9 (May 1973): 150155 .

Zorabedian, Tom. The View From our Side: Sex and Birth Control for Men. Atlanta, Georgia: Emory University Family Planning Program, 1975. 
APPENDIX A

CHI SQUARE TABLES

TABLE XVI

Birth Control decision-making correlated with felt responsibility, males only.

Desire to be more involved in decision-making.

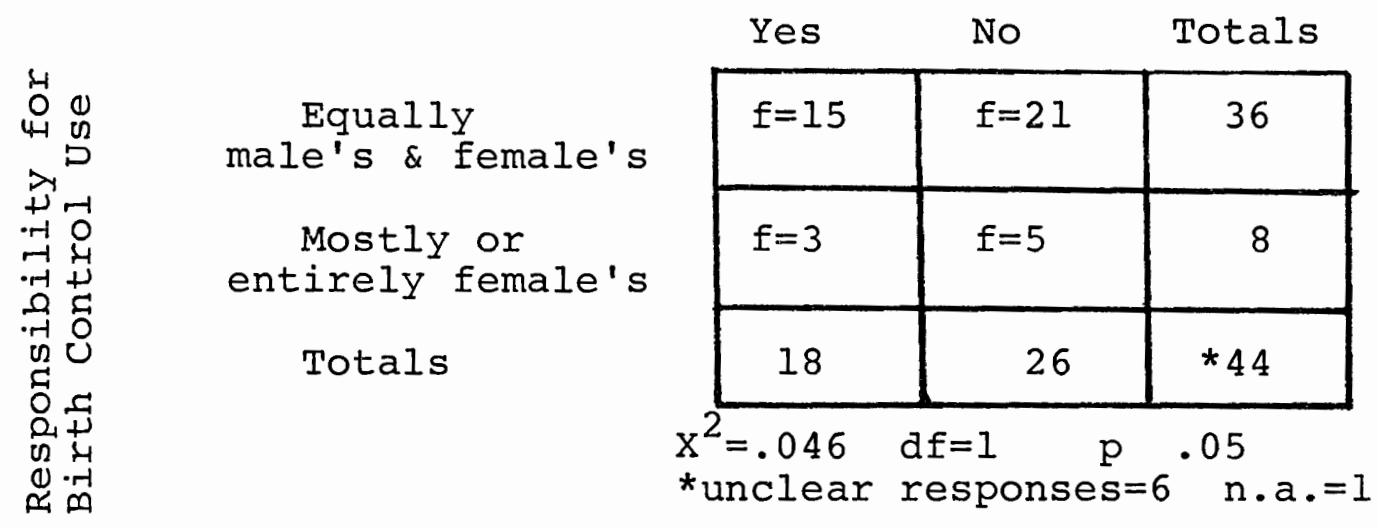

TABLE XVII

Consent to sexual intercourse without Birth Control Number of Responses

\begin{tabular}{|c|c|c|c|}
\hline \multirow{2}{*}{$\begin{array}{l}\text { Response } \\
\text { Yes }\end{array}$} & Male & Female & Totals \\
\hline & $f=14$ & $f=12$ & 26 \\
\hline No & $f=17$ & $f=20$ & 37 \\
\hline Sometimes & $f=19$ & $f=19$ & 38 \\
\hline Totals & *50 & 51 & 101 \\
\hline & $\begin{array}{l}x^{2}=. \\
*=n .\end{array}$ & $d f=2$ & .05 \\
\hline
\end{tabular}


TABLE XVIII

\section{INITIATOR OF VISIT TO PPP, BY SEX}

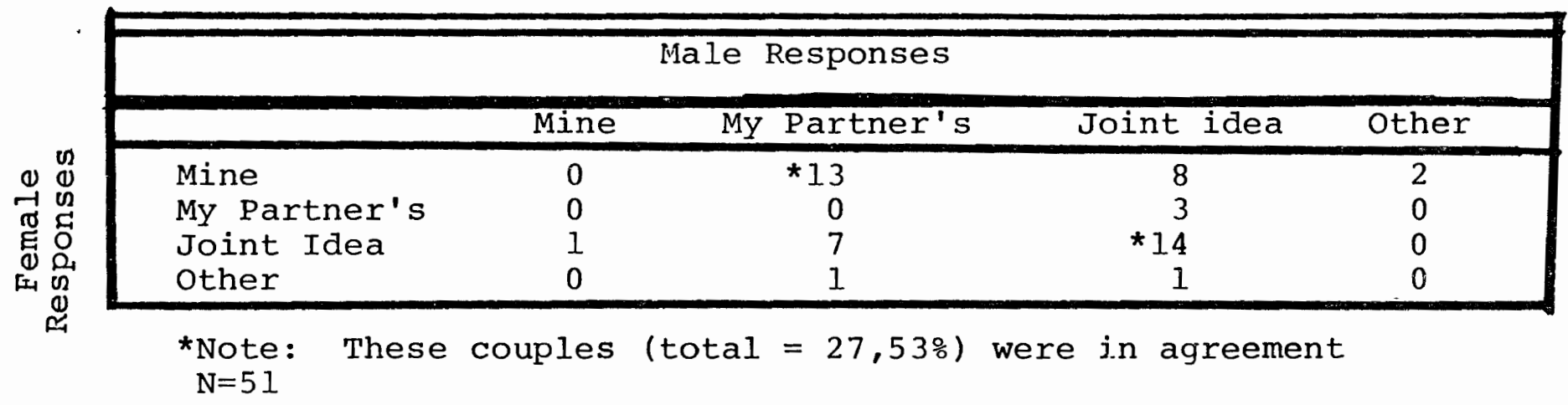

TABLE XIX

FELT INVOLVEMENT IN DECISION-MAKING

Male Responses

\begin{tabular}{|lccccc|}
\hline & Not & Equal with & I make & $\begin{array}{c}\text { Partner's } \\
\text { Decisions } \\
\text { Besponsibility }\end{array}$ \\
\hline Not at all & 0 & Some & Dartner & 0 & 0 \\
Some & 0 & 0 & 1 & 0 & 1 \\
Equal with partner & 0 & 6 & $* 33$ & 0 & 0 \\
I make decision & 0 & 1 & 5 & 1 & 0 \\
Partner's responsibility & 0 & 0 & 0 & 0 & 0 \\
\hline
\end{tabular}

*Note: These couples $(65 \%)$ were in agreement $\mathrm{N}=51$ 




\section{APPENDIX C}

\section{Men's Comments}

Suggestions for improving the services for men at Planned Parenthood.

- A question and answer session for partners and somebody in the know (doctor).

- There are some new and very interesting birth control methods for men. The "Cold Valve" which is turned on and off by a physician. There should be signs and information, such as brochures especially for men. And possibly someone who really known their shit.

- Not received any.

-- I don't know enough about the agency to tell right now.

-- Get a lot better rubbers. Ones that feel good instead of feeling like taking a bath with your socks on.

-- Seems ok to me.

- I was not aware of the fact that they had services for men here.

-- Maybe some more men working at the desk.

- Have more male help.

- Doing a fine job.

-- I do not know what services there are.

- Please continue to help educate all who'd listen or ask for your services.

-- Explanation of the principle behind the use of misuse of the available methods of birth control.

-- I think that they should let the man become more involved in the way of classes and counseling.

-- I don't know enough about existing services here.

-- I haven't had a chance to see how they work with men. 


\section{Men's Comments (continued)}

-- Since I have not used the services at PP and am aware of my alternatives in terms of birth control, I feel that services are adequate.

-- I have never really had a personal problem of my own so I could not really say. My partner is the one I came here for.

-- Men don't realize there are any services for men. Somehow male involvement is needed, starting with going to meeting groups and telling people (men). Mixed male and female groups to start with. 


\section{Men's Comments}

Concluding comments, gripes, feelings or information for the researchers and/or the clinic.

-- You are doing a good job.

-- I can't think of anything right now.

-- I think that Planned Parenthood does a very good job and they keep things confident.

-- I appreciate the anonymity each and every person is treated with. Even the magazine selection is good for us male stander-byers.

-- Develop a reversible vasectomy and you've got it made.

-- Try to keep closer to scheduled appointment times.

-- It would be nice to learn more information about safe birth control methods other than the pill. I have heard of dangers of prolonged use, and would prefer my partner to take a break from the pill.

-- Planned Parenthood provides a valuable resource to the community.

-- It's a very fine program. You make birth control available to anyone who wants it. If people aren't using your services that's their problem.

-- I think that they are doing a splendid job.

-- Why dosen't someone make a birth control pill for the male.

-- I am sterile.

-- Takes too long before you get to see a doctor.

-- I would like to accompany my wife through the entire procedure so as to make it emotionally easier for her along with increasing my knowledge at the latest birth control methods--and the way this organization handles this ever so important responsibility. In relation to giving physical birth control to very young girls who realize it is necessary but $I$ also believe it is important for them to have added counseling so as to help them handle this act in a positive way and not as an escape as so many involved youngsters do. 
Men's Comments (continued)

-- Do you think you could progandize young teens to use birth control as a matter of course before even the first sexual contact is expected? If you weren't run out of town, it might do a little good.

-- The rubbers at Planned Parenthood are redlly screwed. Almost all rubbers are really fucked because they cut down too much sensation. Also, the good ones are too damn expensive.

-- Counseling at no cost--good idea. We started going to private doctor but the costs were too great for us at this time.

-- It seems to me to be a good community service. But I don't tell the people who need it the most are getting it easily (the poor and illiterate).

-- Someone one adopted me when I was 13 months.

-- You're doing a good job, all I can say is maybe more education at the grade and high school level and not just on birth control but also sexuality. 


\section{APPENDIX D}

Women's Comments

Suggestions for improving the services for men at Planned Parenthood.

-- A pool table.

- I don't know what these services would be. Have not seen too many men around PP. I believe seminars (lectures) are valuable in informing men about the female contraceptives as most are pitifully unaware of the problems that occasionally incur upon the user.

- Make them understand that women have problems with sexual things that are caused by mental problems.

- only if you came up with a male pill or a definitely reversible vasectomy (until we've been married awhile longer and are SURE we want no children).

- I feel that there should be methods of birth control for men as well as women.

- I think service is great.

-- I think men feel uncomfortable here because it's mostly for the female.

-- I don't know enough about your present services to make a comment.

-- Don't even know what the services for men are.

-- Classes for them on birth control.

-- I am not aware of what services are offered now.

-- I think the husband should be allowed to go with you to the examining room, at least while you're talking to the doctor so he can know what's going on.

-- Yes, have your partner with you at all times; inserting and IUD, fitting a diaphram.

-- No--since PP has always been serviceing me without his company except for today. I'm not aware of services men feel they are not receiving. 
Women's Comments (continued)

-- If we can fly a man to the moon we can certainly find more methods of birth control for a man. Planned Parenthood is great.

-- I have heard rumors about birth control pills for men that are not in use because men want to leave birth control up to women. If there is such a thing I would like to have information from Planned Parenthood so I can find out fact from fallacy.

-- A publication or class in female sexuality and/or birth control. Very few men understand how a baby is made and many men need to be sensitive to women's sexual needs.

-- I think that if a woman comes in with her partner to get some sort of birth control that the partner should have to go to that class that we do the very first time we come to Planned Parenthood.

-- No. I think they are doing just fine. Now if they could only get more men to come.

-- I think PP should try to involve men more in birth control methods. The men should be encouraged to get exams. It would be nice to hold an occasional class directed at male sexuality.

-- Only that any information on newer male contraceptives (if any) should be given.

-- Well done.

-- I think they should be with us through the meetings and everything to help make decisions and see what we go through. But I tell my boyfriend everything anyways so its allright.

-- I am unsure of what programs are not available for men but would suggest discussion groups might be a good way of making men more aware of a need for birth control.

-- Not really familiar with the services for men.

-- Include partners more in cases where herpes or such viruses occur -- they need to understand the female's discomfort. 
Women's Comments

Concluding comments, gripes, feelings or information for the researchers and/or the clinic.

- Very good service. Sometimes a long wait but this is understandable. Very plesant staff and well qualified doctors.

- I have found that the people here are always friendly and courteous. I very much like and appreciate planned Parenthood.

-- Everything is fine, everyone is pleasant and very helpful.

-- The field of male contraceptives needs to be broadened so that it can take some of the burden off women.

-- I think the doctors that examine me are very good. They always tell me exactly what they are doing and seem to be patient. Lots of people need to know Planned Parenthood exists.

-- Try to get more men to realize that birth control isn't only a woman's worries.

-- My only gripe is that I have used the IUD continuously for $1 \frac{1}{2}$ years and have had two unplanned pregnancies during that time.

-- I really can't think of any. Have been quite pleased with Planned Parenthood.

-- You make me feel stupid and guilty for having fears instead of reassuring.

-- All doctors should be more aware of the additional birth control needs when using the IUD at first.

- Glad to know someone's here.

- I like it. It's free.

-- Get more information out to the general public about VD.

-- We used the pill for approximately 6 years, but after stopping for a period of time, decided they were too dangerous to go back to.

-- Planned Parenthood is excellent. 
Women's Comments. (continued)

-- I have had training in questionnaire construction and want to comment on the quality of your questionnaire (good). It has a few biases that I can see, except that it seems as though question 21 is directed at a woman.

-- Questions 16 and 17 are hard to answer. He understands preganncy and birth control but what do you mean by sexuality? Its relation to or his knowledge of technique? We were both virgins before that night and both unknowledgeable. We have used condoms. He does not like them. We have used withdrawal but would not now that I'm on the pill. I would consent to intercourse with my husband without $B C$ if need be again, but I don't need to.

-- Since I have been with my partner I have had just one problem after another either birth control or mental things. He finds it hard to understand mental. I use the diaphragm but it's really a hassle.

-- I respect the Planned Parenthood and fully support and recommend it to friends in need. Always an excellent staff. PS: an incredible amount of paper must go to waste with those persisting green forms to be filled out each visit.

-- More information involving alternative BC methods for men. 


\section{APPENDIX E}

\section{INVOLVING MEN IN FAMILY PLANNING *}

I

IDEAS

1. Involve men in clinic discussion, interviews, counseling, follow-ups.

2. Invite women to bring partners (e.g., in phone interview).

3. Include men in examinations.

4. Staff education, training, awareness.

5. Expand outreach and education programs in clinic, community, schools.

6. More men on staff and volunteering: lead, co-lead raps.

7. More male involvement in pregnancy counseling, staff and client.

8. New education and information programs for men (e.g., sexual groups, programs for unwed fathers).

9. Examine own attitudes, skills.

10. Communicate importance of male involvement to agency administration.

II COMMON BARRIERS to the implementation of these plans included:

1. Staff attitudes, staff resistance, sexism, family planning as female domain.

2. Lack of time and staff to include men in clinic programs.

3. Funding.

4. Administrative opposition; agency philosophy, bureaucracy, structure, priorities.

5. Finding willing, qualified men as staff and volunteers.

* Obtained from Seattle Planned Parenthood Author unknown. 
Appendix E (continued)

II

6. Male resistance, lack of motivation, apprehension; macho roles.

7. Lack of space; small exam rooms.

8. Objections of female patients.

9. Community attitudes; cultural, religious, language barriers.

10. Resistance from conservative communities and/or schools.

Steps listed by participants to reduce or eliminate these barriers included:

\section{HOW TO DEAI WITH BARRIERS}

1. Staff screening, training, education.

2. Approach administration; ask for trial and evaluation.

3. Community and client education.

4. Work on own attitudes; self-education.

5. Work more closely with schools and teachers, especially male teachers.

6. Expand physical facilities; change, expand clinic hours.

7. Affirmative action program for hiring men.

8. Advertise; develop brochure for men, inviting them to participate in services. 
The attached questionnatre is part of a research study being carried out by a team of graduate students from Portland State University School of Social Work. We want to know if men's needs for birth control information and services are being adequately met.

Even though some of the questions may seem rather personal, they have been designed to obtain valuable information. Your willingness to answer them openly and fully will contribute to our understanding of the sexual noeds of young people and will help us improve our services to others.

We encourage you to flll out the questionnalre, but you are under no obligation to do so. If you choose not to participate, simply return the questionnatie to the receptionist.

Thank you for your time and interest.

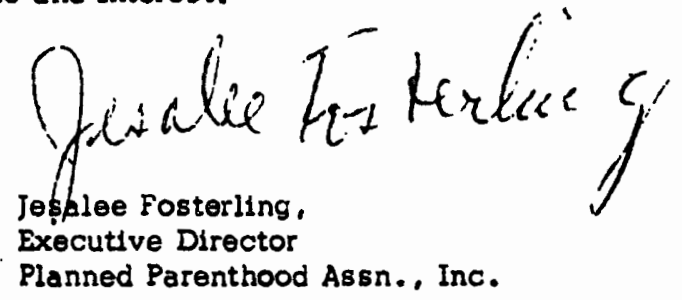

\section{INSTRUCTIONS}

1. Please do not give your name. The questlonnaire will be completely confidential. To protect your privacy, only the researchers will see the questionnaires.

2. Unless otherwise instructed, please try to answer ald the questions as best you can by checking the one choice you feel best describes your opinion or situation.

3. When you have finished, please seal the questionnaire in the attached envelope and return it to the recoptionlst.

4. Please do not discuss the se questlons with your partner while filling out the questionnaire. It is important that they be answered independentiy. 
$-2-$

FIRST, WE WOULD LIKE SOME GENERAL INFORMATION ABOUT YOU.

1) What is your age?

-1

2) What is your present marital situation? married

Dnever married separeted

divorced

3) Are you presently living whth your sexual partner? Yes No

4) Please ctrcle the number of years you have completed in school.

$\begin{array}{llllllllllllllllll}1 & 2 & 3 & 4 & 5 & 6 & 7 & 8 & 9 & 10 & 11 & 12 & 13 & 14 & 15 & 16 & 17 & 18\end{array}$

5) How far in school do you plan to go?

finish grade school some high school finish high school some college finish college post-graduate work some technical or speclal training. Please indicate what kind: 
6) Whose idea was it to come to Planned Parenthood? mostly mine mostly my partner's joint decision other. Please explain

7) Where did you go to obtain birth control before coming to Planned Parenthood? friend vending machine drug store

\begin{tabular}{l} 
vending machine \\
\hline parents \\
didn't obtain
\end{tabular}
brother or slster private doctor other. Please explain

8) Why did you come to Planned Parenthood? (you may answer more than one.) to keep partner company to provide transportation to make sure partner came becaure I was curlous partner made me come to get more information on birth control

9) Once you arrived how comfortable were you in the watting room?

very comfortable
comfortable
uncomfortable

Comments

10) Have you and your partner discussed the use of birth control? yes no

If "no" did you assume your partner was using a method of birth control?

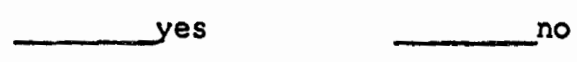

11) How involved do you feel about making decislons regarding the use of a birth control method? not at all equal with my partner some it is my partner's responsibility to make the decisions

12) Would you like to be more involved in the decision-making process of choosing a birth control method? yes no

13) Whose responsibility do you think it ought to be to use birth control to prevent pregnancy? mostly the man's responsibility entirely the man's responslbillty mostly the woman's responsibility entirely the women's responsibllity equally the man's and woman's responsibility 
$-4-$

14) The services offered to your partner at Planned Parenthood include counseling, classes and physical examinations.

$\cdot x$

If it were possible and your partner agreed, would you like to accompany her to any or all of these services?

counseling

classes

physical exam
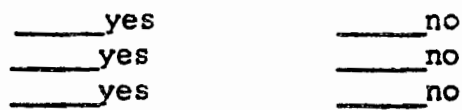

15) Please check any of the following methods of birth control you would NOT be willing to use or have your partner use:

foam
condom(rubber)
foam with condom
diaphragm
male sterllization
ivasectomy)

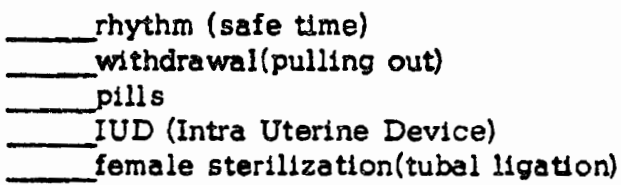

16) Please check any of the following methods of birth control you think your partner would be unwilling to use or have you use:
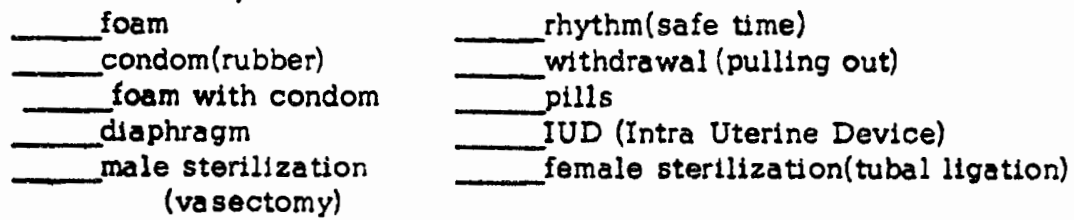

17) If you answered "condom" to the above question why wouldn't you use a condom?

reduces sexual pleosure

too much hassle

do not feel it is a successful method of birth control

I would be embarrassed

my partner did not want to

other. Please explain

18) If condoms were less expensive, do you think you:

would begin to use the $\mathrm{m}$

would use them more often than now

wouldn't use them anyway

(see reverse slde) 
$-5-$

It has been shown that sexual attitudes relate to birth control use. Arswers to the following questions will help us in planning our educational and outreach program.

13) How old were you when you first had sexual intercourse? years of age I have not yet had intercourse.

20) At the time of your first sexual intercourse with your current partner, would you: say that your knowledge of facts about sex, pregnancy, and birth control was:

excellent or very good
good not appiscable(we have not had

21) How would you rate your present knowledge of facts about sexuality, pregnancy and bi rth control? excellent or very good good

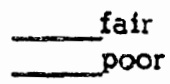

22) How old were you when you first used birth control? I am not yet using birth control

23) Have you ever gotten a woman pregnant when you didn't mean to? yes no

24) Who generally takes the lead in having sexual intercourse? you your partner

both together

25) Would you consent to sexual intercourse with your partner even if you or she were not using birth control?

yes no sometimes

26) About how many of your male friends do you think are having sexual intercourse without using blrth control? ust a few some quite a lot

THERE ARE ONLY A FEW MORE!! ON THE FOLIOWING QUESTIONS, YOU MAY CHECK MORE THAN ONE CHOICE.

27) Have you ever attended a class about:

birth control?

male sexuallty?

female sexuallty?
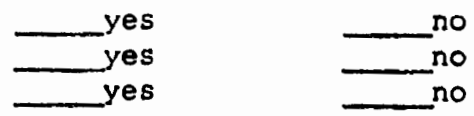

28) Would you like to know more about birth control? yes no

21) Would you attend a special group session relating to: birth control ? male sexuality? female sexuality?
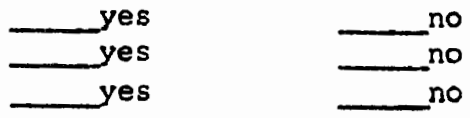

(continued) 


\section{APPENDIX G}

Female's Questionnaire

$$
-2-
$$

FIRST, WE WOULD LIKE SOME GENERAL INFORMATION ABOUT YOU.

1) What is your age?

2) What is your present marital situation?

\begin{tabular}{c} 
martied \\
never maried \\
separated \\
\hline divorced
\end{tabular}

3) Are you presently living with your sexual partner? Yes No

4) Please circle the number of years you heve completed in school.

$\begin{array}{llllllllllllllllll}1 & 2 & 3 & 4 & 5 & 6 & 7 & 8 & 9 & 10 & 11 & 12 & 13 & 14 & 15 & 16 & 17 & 18\end{array}$

5) How far in school do you plan to go? finish grade school some high school finish high school some college findsh college post-graduate work

some technical or speclal training. Please indicate what kind: 
i) Whose idea was if to come to Planned Parenthood? mostly mine mostly my partner's joint decision other. Please explain

i, Where did you go to obtain birth control bofore coming to Planned Parentlrocd? friend drug store vending machine brother or sister parents private doctor didn't obtain other. Please explain

" $)$ Have you and your partner discussed the use of birth control? Yes No

9) How involved do you feel about making decisions regarding the use of a birth control method? not at all some equal with my partner I make the declsions It is my partner's responsibility to make the decisions

10) Whose responsibility do you think it ought to be to use birth control to prevent pregnancy? mostly the men's responsibllity entirely the man's responsibility mostly the woman's responslbility entirely the woman's responsibllity equally the man's and woman's responsibility

i1) Please check any of the following methods of birth control you would NOT be willing to use or have your partner use:

foam
condom(rubber)
foam with condom
diaphragm
male sterilization(vasectomy)

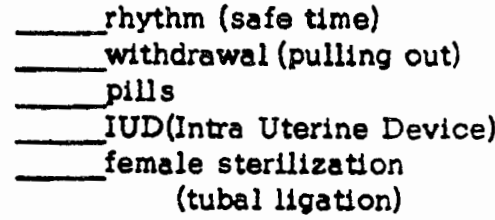

(continued) 
12) Please check any of the following methods of birth control you think your partner would be UNWILIING to use or have you use:

\begin{tabular}{l} 
foam \\
condom(rubber) \\
foam with condom \\
\hline diaphragm \\
male sterilization (va sectomy)
\end{tabular}

13) Do you and your partner ever use condoms? If "no", why not? rhythm(safe time)

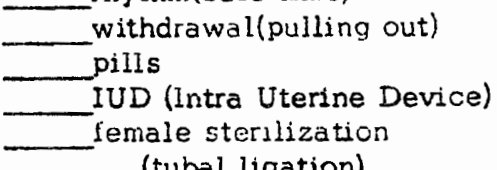

(tubal ligation)

my partner did not want to

reduces sexual pleasure

do not feel it is successful method of birth control

too much hassle

I would be emberrassed

other. Explain

14) If condoms were less expensive, do you think your partner:

would begin to use them

would use them more often than now wouldn't use them anyway

It has been shown that sexual attitudes relate to birth control use. Answers to the following questions will help us in planning our educational and outreach program.

15) How old were you when you first had sexual intercourse? I have not yet had intercourse

years of age

16) At the time of your first sexual intercourse with your current partner, would you say that his knowledge of facts about sex, pregnancy, and birth control was: excellent or very good good falr
poor not applicable(we have not had intercourse)

17) How would you rate your partner's present knowledge of facts about sexuality, pregnancy, and birth control? excellent or very good good

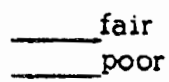

18) How old were you when you first used birth control? I am not yet using birth control

19) Have you ever had an unplanned pregnancy? years of age yes no 
$-j-$

20) Who generally takes the lead in having sexual intercourse? you your partner

both toqether

i) Wi uld you consent to sexual intercourse with your partner even if you cr he were not using birth control?

- yes

yes no no no n

sometimes

22) About hu.: i.sny of your female friends do you think are having sexual intercourse whi: $: \because=$ ing birth control?

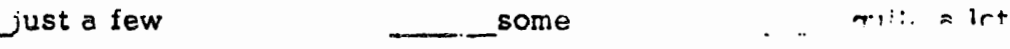

THERE ARE ONLY A FEW MORE!! ON THE I TLLOWING QUESTIONS, YOU MAY CHECK MORE THAN ONE CHOICE.

23) Has your partner ever attended a class about:

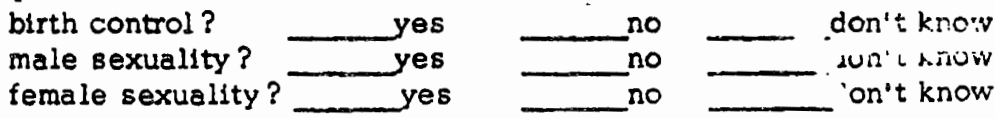

24) Do you think your partner would attend a speclal group session relating to:
birth control?
male sexuality?
female sexuality?
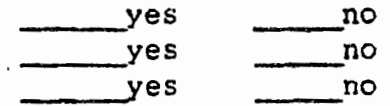
don't know den't know don't know

25) Would you like yci: partner to attend a speclal group session rela:birth control

male sexuality

female sexuality

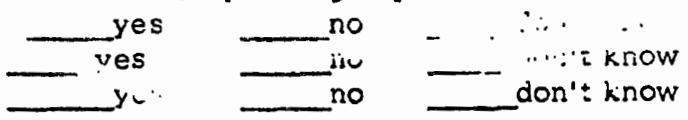

26) Do you think your partner would prefer such a gruur ' the for: men only men and women attending together I do not think it would make a difference I do not think he would attend any group session I do not know

27) Do you have any suggestions for improving the services for men at Planned Parenthood? Please be specific as possible.

28) And finally, please add any comments, gripes, feelincs, information ys: would like us to have, etc.

THAT'S ALL!! PLEASE SEAI THE QUESTIONNAIRE IN THE ENVELOPE PROVIDED AIVD RETURN IT TO THE RECEPTIONIST BEFORE LEAVING. THANK YOU VERY MUCH FOR YOUR PATIENCE AND FOR YOUR ASSISTANCE IN THIS STUDY. 